\title{
Metaproteogenomic analysis of a dominant green sulfur bacterium from Ace Lake, Antarctica
}

\author{
Charmaine $\mathrm{Ng}^{1}$, Matthew Z DeMaere ${ }^{1}$, Timothy J Williams ${ }^{1}$, Federico M Lauro ${ }^{1}$, \\ Mark Raftery ${ }^{2}$, John AE Gibson ${ }^{3}$, Cynthia Andrews-Pfannkoch ${ }^{4}$, Matt Lewis ${ }^{4}$, \\ Jeffrey M Hoffman ${ }^{4}$, Torsten Thomas ${ }^{1,5}$ and Ricardo Cavicchioli ${ }^{1}$ \\ ${ }^{1}$ School of Biotechnology and Biomolecular Sciences, The University of New South Wales, Sydney, New \\ South Wales, Australia; ${ }^{2}$ Bioanalytical Mass Spectrometry Facility, The University of New South Wales, \\ Sydney, New South Wales, Australia; ${ }^{3}$ Marine Research Laboratories, Tasmanian Aquaculture and Fisheries \\ Institute, University of Tasmania, Hobart, Tasmania, Australia; ${ }^{4}$ J Craig Venter Institute, Rockville, MD, USA \\ and ${ }^{5}$ Centre for Marine Bio-Innovation, The University of New South Wales, Sydney, New South Wales, \\ Australia
}

\begin{abstract}
Green sulfur bacteria (GSB) (Chlorobiaceae) are primary producers that are important in global carbon and sulfur cycling in natural environments. An almost complete genome sequence for a single, dominant GSB species (' $C$-Ace') was assembled from shotgun sequence data of an environmental sample taken from the $\mathrm{O}_{2}-\mathrm{H}_{2} \mathrm{~S}$ interface of the water column of Ace Lake, Antarctica. Approximately $34 \mathrm{Mb}$ of DNA sequence data were assembled into nine scaffolds totaling $1.79 \mathrm{Mb}$, representing approximately 19-fold coverage for the $C$-Ace composite genome. A high level $(\sim 31 \%)$ of metaproteomic coverage was achieved using matched biomass. The metaproteogenomic approach provided unique insight into the protein complement required for dominating the microbial community under cold, nutrient-limited, oxygen-limited and extremely varied annual light conditions. $\boldsymbol{C}$-Ace shows physiological traits that promote its ability to compete very effectively with other GSB and gain dominance (for example, specific bacteriochlorophylls, mechanisms of cold adaptation) as well as a syntrophic relationship with sulfate-reducing bacteria that provides a mechanism for the exchange of sulfur compounds. As a result we are able to propose an explanation of the active biological processes promoted by cold-adapted GSB and the adaptive strategies they use to thrive under the severe physiochemical conditions prevailing in polar environments.

The ISME Journal (2010) 4, 1002-1019; doi:10.1038/ismej.2010.28; published online 18 March 2010

Subject Category: Integrated genomic and post-genomic approaches in microbial ecology
\end{abstract}

Keywords: green sulfur bacterium; metagenomics; metaproteomics; cold adaptation; Antarctic meromictic lake; ecological dominance

\section{Introduction}

Green sulfur bacteria (GSB) (Chlorobiaceae) are primary producers that are important in global carbon and sulfur cycling in natural environments (Pfennig, 1975; Overmann, 2006). The GSB are anaerobic photoautotrophs carrying out photosynthesis using light-harvesting chlorosomes and carbon fixation through the reverse tricarboxylic acid (rTCA) cycle (Eisen et al., 2002). Chlorosomes are unique, light-harvesting antennas that are packed with bacteriochlorophyll (BChl) $c, d, e$ and $a$, which enable photosynthesis to occur at low light intensities (Blankenship et al., 1995; Bryant and

Correspondence: R Cavicchioli, School of Biotechnology and Biomolecular Sciences, The University of New South Wales, BABS, Sydney, New South Wales 2052, Australia.

E-mail: r.cavicchioli@unsw.edu.au

Received 25 November 2009; revised 2 February 2010; accepted 11 February 2010; published online 18 March 2010
Frigaard, 2006; Frigaard and Bryant, 2006). GSB can grow mixotrophically through acetate assimilation in the presence of light and $\mathrm{CO}_{2}$. For these photoassimilatory reactions, most GSB use sulfide as an electron donor, although some GSB species are able to oxidize other inorganic reduced sulfur compounds (for example, sulfur, polysulfides, thiosulfate and tetrathionate), as well as hydrogen and/or ferrous iron (Frigaard and Bryant, 2008). The oxidation of sulfide results in the production of sulfate, and in some instances, the accumulation of sulfur deposits outside the cells (Frigaard and Bryant, 2008). In some anaerobic aquatic systems, syntrophic interactions take place between GSB and sulfate-reducing bacteria (SRB). When this occurs, the sulfate produced from the activity of GSB is used as a terminal electron acceptor by SRB, which in turn is converted to biogenic sulfide. GSB therefore contribute to the sulfur cycle by oxidizing sulfur compounds, and when they coexist with SRB they 
cooperatively create a complete sulfur cycle, a matter of importance in closed lake systems (Pfennig, 1978; Biebl and Pfennig, 1978).

Green sulfur bacteria are typically found thriving in freshwater and estuarine environments where light is limited, and the waters are anoxic and rich in sulfide. Their habitats include sediments, microbial mats, sulfide-rich hot springs and within a discrete zone of the water column of stratified lakes where light is able to penetrate to the anoxic zone (Wahlund et al., 1991; Ward et al., 1998; Vila et al., 2002; Mallorqui et al., 2005; Martínez-Alonso et al., 2005; Musat et al., 2008). GSB have also been identified in marine environments where light penetration is very limited, at the chemocline of the Black Sea (Manske et al., 2005), and in the benthos near deep-sea hydrothermal vents in the Pacific Ocean (Beatty et al., 2005).

In East Antarctica, an area called the Vestfold Hills contains numerous marine-derived saline lakes that were formed when the ocean receded approximately 5700 years ago (Gibson, 1999; Rankin et al., 1999; Cavicchioli, 2006). Fjords connected to the ocean also cut across the Vestfold Hills. Ellis Fjord is $10 \mathrm{~km}$ long, up to $100 \mathrm{~m}$ deep and has become a stratified system due to its restricted opening (less then $4 \mathrm{~m}$ deep) to the ocean (Burke and Burton, 1988b). In more than a dozen of the stratified systems that have anoxic bottom waters (lakes, marine basins and fjords), members of the Chlorobiaceae (that is, Chlorobium limicola and Chlorobium vibrioforme) have been reported to be the dominant type of GSB (Burke and Burton, 1988a b). In Ellis Fjord, the $\mathrm{O}_{2}-\mathrm{H}_{2} \mathrm{~S}$ interface where GSB have been observed is at a depth of $\sim 40 \mathrm{~m}$ beneath the surface where measurable quantities of light $\left(0.1 \mu \mathrm{E} \mathrm{m}^{-2} \mathrm{~s}^{-1}\right)$ have been detected during summer. Chlorobium species have been grown from samples taken at a depth of $100 \mathrm{~m}$ below the surface, and based on rates of sedimentation, the GSB in Ellis Fjord were predicted to have survived in the dark for $>4.5$ years. The capacity of the Chlorobium species to dominate has been speculated to be due to a superior ability to harvest the intensity and wavelength of available light during the Antarctic summer (for example, compared to members of the Chromatiaceae), and to remain viable during winter (Burke and Burton, 1988a,b). Isolated Chlorobium species have been noted for their ability to grow well in hypersaline water at $-2{ }^{\circ} \mathrm{C}$, and to grow at very low light intensities $\left(<1 \mu \mathrm{E} \mathrm{m}^{-2} \mathrm{~s}^{-1}\right.$; Burke and Burton, 1988a, b).

Ace Lake (in the Vestfold Hills) is the most thoroughly studied meromictic lake in Antarctica (Rankin et al., 1999), and it is the subject of a comprehensive environmental genomic/proteomic program. The lake surface remains covered in approximately $2 \mathrm{~m}$ of ice for about 10-11 months (February/March-December) of the year and usually (but not always) melts out during summer (January) (Gibson, 1999; Rankin et al., 1999). Mixing in the upper waters of the lake is caused by exclusion of salt from the forming ice cover in winter, and by wind mixing when the lake is ice free. A strong midwater halocline prevents penetration of mixing to deeper waters. The oxygen content in surface waters of the lake is high, and rapidly decreases at the chemocline where a pronounced $\mathrm{O}_{2}-\mathrm{H}_{2} \mathrm{~S}$ interface exists. Phytoplankton species (for example, Pyramimonas gelicola, Mesodinium rubrum), cyanobacteria and photosynthetic microorganisms in microbial mats (for example, cyanobacteria, diatoms, algae) are likely to contribute to primary production in the oxic zone of the lake. Primary productivity measurements of Ace Lake indicate that the autotrophic ciliate, $M$. rubrum, which has also been found in Antarctic waters is a major contributor to carbon fixation (15-40\%) during its bloom period over summer (Labourn-Parry and Perriss, 1995; Rankin et al., 1999). Autotrophic primary producers convert inorganic carbon to biomass $(0.16-0.68 \mathrm{mgC}$ $\mathrm{m}^{-3} \mathrm{~h}^{-1}$ ), and in the process release dissolved organic carbon by the action of predation and viral lysis (dissolved organic carbon: 6-11.5 mgC $\mathrm{l}^{-1}$ ) (Rankin et al., 1999). Owing to physical stability, dissolved organic carbon is likely to cycle within the aerobic zone. Dead cell material from all organisms and fecal pellets ( $P$. antarctica) forms particulate organic carbon that gradually sinks (particulate organic carbon: $0.22-0.73 \mathrm{mgC}^{-1}$ ) (Rankin et al., 1999).

At the interface, a brief period ( $\sim 6$ weeks) of high light intensity occurs after the ice cover has melted during summer allowing maximum light penetration (maximum recorded $\sim 100 \mu \mathrm{mol}$ of photons $\mathrm{m}^{2} \mathrm{~s}^{1}$ ) and enabling the most rapid growth of photosynthetic populations (Burke and Burton, 1988b). The lake experiences a longer period of intermediate light intensity $(<30 \mu \mathrm{mol}$ of photons $\mathrm{m}^{2} \mathrm{~s}^{1}$ ) over summer when the ice cover has not melted, and a period ( $\sim 6$ weeks) of almost complete darkness during winter (Burke and Burton, 1988b). Chlorobium species of GSB have been identified at this $\mathrm{O}_{2}-\mathrm{H}_{2} \mathrm{~S}$ interface (Burke and Burton, 1988b; Coolen et al., 2006), and sulfate reduction by SRB has been reported in the region below the chemocline (Franzmann et al., 1988; Rankin et al., 1999). No axenic cultures of GSB have been obtained from Ace Lake or any of the systems in the Vestfold Hills, limiting physiological and molecular analyses. In contrast, mesophilic and thermophilic counterparts are available, including the complete genome sequences of 12 GSB species that range in size from $1.97 \mathrm{Mb}$ for Prosthechochloris vibrioformis DSM 265 to $3.3 \mathrm{Mb}$ for Chloroherpeton thalassium ATCC 35110. The first and most comprehensively characterized genome sequence is for the thermophile, Chlorobaculum tepidum TLS (Eisen et al., 2002), which was isolated from a hot spring in New Zealand (Wahlund et al., 1991).

In this study, microbial biomass was sampled from the turbidity peak coinciding with the halocline and 
oxycline in Ace Lake, and analyzed by metagenomic sequencing and metaproteomic mass spectrometry. The sample was highly enriched for a single, dominant bacterium (referred to as ' $C$-Ace') enabling a large assembly for a composite genome of the bacterium and high coverage of the proteome to be achieved. As a result we have been able to assemble a hypothetical model of the active biological processes mediated by $C$-Ace and propose a number of adaptive strategies it may use in response to physiochemical conditions prevailing in the lake, including seasonal changes in solar radiation.

\section{Materials and methods}

\section{Antarctic samples}

Water samples were collected from Ace Lake $\left(68^{\circ}\right.$ $28.33^{\prime} \mathrm{S}, 78^{\circ} 11.29^{\prime} \mathrm{E}$ ), Vestfold Hills, Antarctica on 22 December 2006. A $2 \mathrm{~m}$ hole positioned above the deepest point ( $25 \mathrm{~m}$ depth) of the lake was drilled through the ice cover of Ace Lake to enable sampling of lake water. A volume of 1 and 10 liters was pumped directly from the lake and collected by sequential size fractionation through a $20 \mu \mathrm{m}$ prefilter onto filters $(3,0.8$ and $0.1 \mu \mathrm{m}$ pore-sized, $293 \mathrm{~cm}$ polyethersulfone membrane filters; Rusch et al., 2007) from depths of $12.7 \mathrm{~m}$ (Supplementary Figure S10) and $14 \mathrm{~m}$, respectively. Two independent sets of filters were obtained. Filters were placed into a tube containing a solution of $2.5 \mathrm{mM}$ EGTA, $2.5 \mathrm{mM}$ EDTA, $0.1 \mathrm{mM}$ Tris-EDTA (pH 8), $1 \mathrm{mM}$ PMSF (freshly prepared), $50 \mu \mathrm{l}$ of protease inhibitor cocktail VI (Calbiochem, San Diego, CA, USA) and the tubes placed into liquid $\mathrm{N}_{2}$ before storage at $-80^{\circ} \mathrm{C}$. The protease cocktail inhibitor has a broad specificity for inhibition of serine, cysteine, aspartic and metalloproteases within protein extracts.

\section{Metagenomic sequencing, assembly and database construction}

DNA extraction and Sanger sequencing of $0.1 \mu \mathrm{m}$ sized filters was performed at the J Craig Venter Institute in Rockville, MD, USA (Rusch et al., 2007). The scaffolds and annotations will be available via CAMERA and public sequence repositories such as NCBI and the reads will be available via the NCBI Trace Archive. 54282 reads totaling 36688915 bases were generated. Assembly was performed using Celera WGS-Assembler v5.3 (http:// sourceforge.net/projects/wgs-assembler/files/) with a unitigger error rate of $3 \%$ and an estimated genome size of $2.2 \mathrm{Mb}$. Isolation of the dominant organism scaffolds was performed by reference to a Self Organising Map created with Synapse (Peltarion, Stockholm, Sweden), where the per-scaffold featurespace vectors were composed of GC content, assembly read depth and the set of 64 normalized trinucleotide frequencies as calculated by Tetra (Teeling et al., 2004). Clear cluster separation identified nine dominant organism scaffolds with a total extent of $1.79 \mathrm{Mb}$ and average GC content of $52.2 \%$. These nine selected scaffolds contained $92.5 \%$ of all scaffolded reads and $77 \%$ of all reads in the experiment. Coverage for these scaffolds represented 18.95-fold.

\section{Annotation and analysis of predicted protein} sequences

An internally developed annotation pipeline was used, where open reading frame (ORF) prediction was performed using Metagene (http://metagene.cb. k.u-tokyo.ac.jp/metagene/download.html) (Noguchi et al., 2006) and Glimmer (http://glimmer.sourceforge. net/) (Delcher et al., 1999), whereas subsequent functional assignments were derived from searches against the COG, KEGG, NR, SWISS-PROT and TIGRFAM databases by use of blast and hmmer. The COG category distribution was used for assigning general functional predictions to proteins with no known functional information against the other databases. The significant differences in COG composition between the composite genome and the metaproteome were detected with custom Perl scripts based on a bootstrapping resampling method (Rodriguez-Brito et al., 2006). A confidence interval of $99 \%$ was established using 10000 subsamples of 750 proteins. The KEGG category assignments and the Metacyc database (http:// metacyc.org/) were used as a source of reference for reconstructing metabolic pathways. A TMHMM tool (http://www.cbs.dtu.dk/services/TMHMM/) and SignalP 3.0 (http://www.cbs.dtu.dk/services/SignalP/) were used to determine the proportion of proteins with transmembrane domains and signal peptides within the proteomic data set. MEGAN (ttp://www-ab.informatik.uni-tuebingen.de/software/ megan) was used to analyze the database of all predicted protein sequences (including those that did not belong to the nine dominant scaffolds) from Metagene to distinguish between proteins taxonomically conserved within sequenced species of the Chlorobiaceae family, and those that fell outside this group. A blastp comparison (e-value $<1 \mathrm{E}-5$ ) was performed on all predicted proteins against the NR database and MEGAN was used with default parameters to generate a phylo profile for all predicted proteins, enabling binning of sequences conserved in Chlorobiaceae and those which were novel to this taxon.

Protein extraction from filter membranes A combination of different physical (sonication/ freeze-thaw) and chemical (urea/SDS containing buffers, TCA precipitation) extraction techniques was tested on filtered ocean water samples to develop a method to maximize recovery of wholecell protein extracts from total biomass on membrane filters. The $0.1 \mu \mathrm{m}$ membrane filters (12.7 and $14 \mathrm{~m}$ samples) were removed from their storage 
buffer and cut into quarters using aseptic procedures. Separate extractions were performed on three of the filter quarters. Approximately $1 \mathrm{mg}$ of protein was extracted from $\frac{3}{4}$ of the $0.1 \mathrm{um}$ membrane in which a total volume of 1 liter of water was filtered. The filters were suspended in a lysis buffer containing $10 \mathrm{~mm}$ Tris-EDTA (pH 8.0; Univar, Sydney, New South Wales, Australia), $20 \mu$ of PI VI (Calbiochem), $0.1 \%$ sodium dodecyl sulfate (SDS; Univar) and $1 \mathrm{~mm}$ dithiothreitol (Sigma-Aldrich, Sydney, New South Wales, Australia). Filters were subjected to three freeze-thaw cycles in liquid $\mathrm{N}_{2}$ to release cells from the membrane. The buffer containing the cells was disrupted on ice by sonication with a Branson Sonifier for five cycles of $40 \mathrm{~s}$ on a $30 \%$ duty cycle at a power setting of 3 . The supernatant containing the extracted proteins was centrifuged at $5000 \mathrm{~g}$ for $25 \mathrm{~min}$ at $4{ }^{\circ} \mathrm{C}$ to remove cell debris. To remove particles that did not pellet during the centrifugation step, we filtered the protein suspension through a $0.22 \mu \mathrm{m}$ syringe filter (Millipore, Sydney, New South Wales, Australia) and transferred into a $5 \mathrm{kDa}$ cutoff Amicon Ultra-15 filter unit (Millipore). Proteins were desalted by performing a buffer exchange with $30 \mathrm{ml}$ of $10 \mathrm{mM}$ Tris-EDTA (pH 8.0) followed by concentration to a smaller volume $(\sim 1 \mathrm{ml})$. Using a bicinchoninic acid protein assay kit (Sigma-Aldrich), we determined final protein concentrations to be between 100 and $500 \mu \mathrm{g}$ per filter.

\section{One-dimensional SDS-PAGE and in gel trypsin digestion}

Protein samples were suspended in appropriate volumes of SDS-PAGE sample buffer and resolved on a $12 \%$ SDS gel using a Mini-PROTEAN system (Bio-Rad, Sydney, New South Wales, Australia) under conditions described previously (Saunders et al., 2006). The gels were stained in silver (Blum et al., 1987) and profile images were acquired using a UMAX PowerLook 1000 flat-bed scanner (Fujifilm, Berthold, Melbourne, Australia). Wholegel lanes were excised using a sterile, clean scalpel and were cut into individual slices. The gel slices were further cut into smaller gel pieces and washed twice in sterile Milli-Q water followed by washing with acetonitrile. The gel pieces were treated through a series of reduction, alkylation and dehydration steps. In gel enzymatic digestion was performed by rehydrating the gel pieces in a buffer containing $\sim 200 \mathrm{ng}$ of trypsin (Promega, Sydney, New South Wales, Australia) in $10 \mathrm{mM}$ of $\mathrm{NH}_{4} \mathrm{HCO}_{3}$ at $37^{\circ} \mathrm{C}$ for $14 \mathrm{~h}$, and peptides were extracted using acetonitrile and dried in vacuo.

\section{Liquid chromatography and mass spectrometry}

Peptide digests were rehydrated in a buffer containing $1 \%$ formic acid and $0.05 \%$ heptafluorobutyric acid. Digested peptides were separated by nano-LC using an Ultimate 3000 HPLC and autosampler system (Dionex, Amsterdam, the Netherlands). Samples $(2.5 \mu \mathrm{l})$ were concentrated and desalted onto a micro C18 precolumn $(500 \mu \mathrm{m} \times 2 \mathrm{~mm}$; Michrom Bioresources, Auburn, CA, USA) with $\mathrm{H}_{2} \mathrm{O}: \mathrm{CH}_{3} \mathrm{CN}$ (98:2, $0.05 \%$ heptafluorobutyric acid) at $20 \mu \mathrm{min}^{-1}$. After a $4 \mathrm{~min}$ wash the precolumn was switched (Valco 10 port valve; Dionex) into line with a fritless nano column $(75 \mu \times \sim 10 \mathrm{~cm})$ containing C18 media ( $5 \mu, 200 \AA$ Magic; Michrom) manufactured according to Gatlin (Gatlin et al., 1998). Peptides were eluted using a linear gradient of $\mathrm{H}_{2} \mathrm{O}: \mathrm{CH}_{3} \mathrm{CN}$ (98:2, 0.1\% formic acid) to $\mathrm{H}_{2} \mathrm{O}: \mathrm{CH}_{3} \mathrm{CN}$ (64:36, $0.1 \%$ formic acid) at $350 \mathrm{nlmin}^{-1}$ over $30 \mathrm{~min}$. High voltage $(1800 \mathrm{~V})$ was applied to the low volume tee (Upchurch Scientific, Oak Harbor, WA, USA) and the column tip was positioned $\sim 0.5 \mathrm{~cm}$ from the heated capillary $\left(T=250^{\circ} \mathrm{C}\right)$ of an LTQ FT Ultra (Thermo Electron, Bremen, Germany) mass spectrometer. Positive ions were generated by electrospray and the LTQ FT Ultra was operated in data-dependent acquisition mode. A survey scan $\mathrm{m} / \mathrm{z}$ 350-1750 was acquired in the FT ICR cell (resolution $=100000$ at $\mathrm{m} / \mathrm{z} 400$, with an initial accumulation target value of 1000000 ions in the linear ion trap). Up to the six most abundant ions (>3000 counts) with charge states of $+2,+3$ or +4 were sequentially isolated and fragmented within the linear ion trap using collision-induced dissociation with an activation $q=0.25$ and activation time of $30 \mathrm{~ms}$ at a target value of 30000 ions. $\mathrm{m} / \mathrm{z}$ ratios selected for mass spectrometry-mass spectrometry (MS/MS) were dynamically excluded for $30 \mathrm{~s}$. Peak lists were generated using Mascot Daemon/extract_msn (Matrix Science, Thermo, London, UK) using the default parameters, and submitted to the database search program Mascot (version 2.1; Matrix Science).

\section{MS/MS data analysis and validation of protein identifications}

Peptide identification was performed by database searching using Mascot. Mascot distiller (Applied Biosystems, Foster City, CA, USA) was used as the data import filter with the following criteria applied to the MS/MS ion search: a maximum of once missed cleavage for trypsin, peptide mass tolerance of \pm 4 p.p.m., a fragment mass tolerance of $\pm 0.6 \mathrm{Da}$ and variable modifications of acrylamide, carbamidomethyl and oxidation. The spectra generated from the $0.1 \mu \mathrm{m}$ protein extraction of the $12.7 \mathrm{~m}$ sample were searched against the total assembled sequence database and the $14 \mathrm{~m}$ sample was searched against the NR database (January 2008). To discriminate between false-positive and confident peptide matches, validated candidate peptides against a decoy database to calculate the false discovery rate (FDR) in the Mascot searches. The decoy database consisted of shuffle sequences from all the peptides in the $C$-Ace and NR databases. The same sets of data were searched against their respective shuffle 
databases, consisting of randomized amino-acid sequences to estimate false-positive protein matches. A cutoff score was established by adjusting the ion score to a value that, when the following formula was applied $2\left(n_{\text {shuf }} /\left(n_{\text {shuff }}+n_{\text {real }}\right)\right)$, resulted in a peptide FDR of $\leqslant 5 \% \quad\left(n_{\text {shuf }}=\right.$ no. of peptides identified against shuffle database, $n_{\text {real }}=$ no. of peptides identified against real database). A second tier of data validation was applied where protein matches were accepted only if they were identified by a minimum of two peptides on the basis that one of the peptides had to be unique (that is, not matched against any other protein).

\section{Results and Discussion}

\section{Overview of the proteogenomic data set}

A metagenomic assembly derived from samples taken from the $12.7 \mathrm{~m}$ zone of Ace Lake revealed large scaffolds with a high level of similarity to genome sequences of GSB, in particular, $P$. vibrioformis DSM 265. As a first indication, of all ORF predictions derived from scaffolds greater than $10 \mathrm{~kb}$, $76 \%$ were assigned first to $P$. vibrioformis DSM 265 when searched against the NCBI NR database (e-value $<1 \mathrm{E}-5$ ). Further, the 10 most frequently assigned organisms were all from the Chlorobiaceae family, accounting for $85 \%$ of all assignments. A composite genome of the most abundant organism was constructed after assembly by the identification of scaffolds that clustered tightly together in featurespace (see Materials and methods). This resultant composite genome was composed of nine scaffolds totaling $1.79 \mathrm{Mb}$, similar in size $(1.97 \mathrm{Mb})$ for $P$. vibrioformis DSM 265. Aligned using Nucmer (Kurtz et al., 2004), this composite genome covered $68.3 \%$ of the inferred reference $P$. vibrioformis DSM 265 at $86.0 \%$ average nucleotide identity. Metagene and MEGAN were used to predict ORFs and make taxonomic assignments, respectively (see Materials and methods). A total of 1631 genes (Supplementary Table S1) were identified in scaffolds of which 1560 were assigned to the Chlorobiaceae family, and 71 to other taxa (Supplementary Figure S1; Supplementary Table S2). Owing to the high number of matches to GSB in the Chlorobiaceae family, the organismal population represented by the composite genome is referred to as $C$-Ace. In addition to the $C$-Ace genome, phylogenetic profiling of the metagenome data that did not fall within the scaffolds was used for identifying specific genes that might also belong to $C$-Ace and could complete a biological process or pathway. To predict ORFs from the nine scaffolds, in addition to Metagene, we used Glimmer (trained against the largest contig of $C$-Ace). This resulted in a prediction of $17 P$. vibrioformis DSM 265-related genes (not detected by Metagene), in addition to the 1631 genes predicted by Metagene (Supplementary Table S1: genes with 'Glimmer' under 'Gene no.' heading).
For metaproteomics, the biomass from $12.7 \mathrm{~m}$ collected on a $0.1 \mu \mathrm{m}$ filter was extracted and processed through 12 liquid chromatography MS/ MS runs (see Materials and methods) generating approximately $100000 \mathrm{MS} / \mathrm{MS}$ spectra. A total of 689 proteins ( $\sim 42 \%$ of the 1631 predicted proteins) were identified with initial searches against the $C$-Ace genome, and refined to $504(\sim 31 \%$ of predicted proteins) confident protein identifications (FDR < $5 \%$; minimum of two peptide matches; total 3970 unique peptides). Only 2 of the 504 proteins in the metaproteome matched to genes from the group of 71 genes that were assigned to taxa distinct from the Chlorobiaceae family; neither of these genes (159801926 and 159801879) could be assigned functions.

Eighty-nine percent of the total proteins from metaproteomics could be assigned to a COG category, with the largest number represented by Translation, ribosomal structure and biogenesis (J), Energy production and conversion (C) and aminoacid transport and metabolism (E) (Supplementary Figure S2). The Translation, ribosomal structure and biogenesis $(\mathrm{J})$ and Energy production and conversion (C) COG categories were statistically overrepresented in the metaproteome versus the composite genome. In contrast, Cell envelope biogenesis, outer membrane (M), Defence mechanisms (V), Inorganic ion transport and metabolism (P), DNA replication, recombination and repair (L) and General function prediction only (R) categories were underrepresented in the metaproteome. The high representation and relative abundance of proteins from the $\mathrm{J}$ and $\mathrm{C}$ categories is likely to reflect their absolute abundance in the cell and the relative importance they have in enabling growth. In contrast, the reduced representation of proteins in categories $\mathrm{M}$ and $\mathrm{P}$ may relate to the membrane localization of many of the proteins in these categories, and the reduced efficiency of solubilizing these types of hydrophobic proteins during protein extraction.

A total of 45 proteins were predicted to have leader peptides, and 55 to have one or more transmembrane domain (Supplementary Figure S3). The majority of these were annotated with functions in proton/electron, phosphate, sodium, iron and protein transport. A number of others were predicted to be membrane-bound proteases/peptidases, chlorosome proteins or hypothetical proteins.

Major cellular pathways and microbial processes likely to be functional at the time of sampling were reconstructed from metaproteomic (and relevant metagenomic) data, using KEGG and Metacyc databases as references. In addition to the $12.7 \mathrm{~m}$ sample, metaproteomic data were generated from the $14 \mathrm{~m}$ zone (with matches against NR) to examine processes taking place in the anaerobic zone immediately below the oxycline; in particular, the sulfur cycle and possible interactions between GSB and SRB (see Sulfur cycle). 
DNA RNA and protein processing

Fundamental processes related to transcription, translation, DNA replication and repair, cell division, protein folding and secretion were represented in the metaproteome (Supplementary Table S3). Protein secretion in $C$-Ace is likely to occur by mechanisms that include the Sec translocation system. Many components of this system were present in the metaproteome, including the signal recognition particle (159800974), which recognizes the leader peptide sequence of the protein and targets it for transport through the inner membrane of the cell, and the membrane-associated Sec translocase protein subunits, SecA (159800433), SecD (159803634), SecF (159803636), YajC (159800617) and YidC (159803616) (Supplementary Table S3). Several transcriptional regulators were identified (Supplementary Table S3) and one of these, ArsR, may be involved in metal ion resistance and ModE in molybdenum uptake. This may be an important regulator as many metals in the lake are at significantly higher levels than the ocean (Rankin et al., 1999). Moreover, molybdenum is important as a cofactor in the reaction center (RC) of the light-harvesting apparatus (see Photosynthesis), and in several enzymes involved in sulfide oxidation (see Sulfur cycle).

Several DNA processing and nucleic acid binding proteins that have core functions in the biology of the cell may also be important for cold adaptation, as has been reported for other microorganisms (Grau et al., 1994; Mizushima et al., 1997; Graumann and Marahiel, 1999; Lim et al., 2000; Giangrossi et al., 2002; Cavicchioli, 2006; Rodrigues and Tiedji, 2008). These include, DNA gyrase A (159801931), DNA-binding protein HU- $\beta$ (159803292), RecA (159801217), RecN (159802659), DrpA (159803132), a DEAD-box RNA helicase (159802095) and a coldshock protein (159801159) (Supplementary Table S3). In addition, two types of peptidyl-prolyl cis-trans isomerases (Supplementary Table S3) may facilitate protein folding/refolding at low temperature.

\section{Photosynthesis}

The metaproteomic data are strongly supportive of $C$-Ace synthesizing a chlorosome-based photosynthesis system. Many Chlorobia-like chlorosome envelope proteins (CsmA, 159801197; CsmB, 159801265, 159800823, 159803384; CsmC, 159801195; CsmF, 159800523; CsmH, 159802205; CsmJ, 159802353) were detected (Supplementary Table S3; Supplementary Figure S1). In addition, a FennaMatthews-Olsen (FMO) protein (159802469) and three photosystem (Psc) proteins (PscA, 159803328; PscC, 159802726; PscD, 159802326) were detected. Chlorosomes are light-harvesting antenna structures packed with thousands of BChl $c, d$ or $e$ oligomers encased in a protein-associated lipid monolayer (Frigaard et al., 1998; Figure 1). Light energy is funneled from the chlorosome via the baseplate through the FMO proteins into the RC, which is located in the membrane bilayer (Hauska et al., 2001; Hohmann-Marriott and Blankenship, 2007).

The $f m o A$ gene is unique to GSB and has been used as a phylogenetic marker to classify species within the Chlorobiaceae family (Imhoff, 2003). Consistent with the overall best matches of the $C$-Ace genome to GSB, phylogeny inferred from the fmo $A$ gene places $C$-Ace closest to $P$. vibrioformis (Supplementary Figure S4).

The three $C$-Ace genes annotated as $\operatorname{csmB}$ each had highest blastp matches to the single $\operatorname{csmB}$ gene in the genomes of three Chlorobium species (CT2054, Plut_2005 and Cpha266_0202). The genome sequence of $P$. vibrioformis DSM 265 is annotated with three $\operatorname{csm} B$ genes, and blastp matches to $\operatorname{csmD}$ and $\operatorname{csmI}$ from $C$. tepidum could not be identified. It is possible that $C$-Ace encodes multiple $\operatorname{csm} B$ genes and lacks $c s m D$ and $c s m I$ genes as does $P$. vibrioformis, or that $c s m D$ and $c s m I$ are present but were not sequenced. A csmE gene (but not protein) was identified in the metagenome data but was not the part of the composite $C$-Ace genome assembly (see Supplementary Table S3: data for $\mathrm{csm}$ gene functions). Although expression of $\operatorname{csm} A$ is essential for cell viability under photoautotrophic conditions in C. tepidum (Chung et al., 1998), expression of all csm genes may not be necessary for the stability, or affect the biogenesis and light-harvesting function of chlorosomes (Frigaard et al., 2004). Comparisons of GSB csm genes have classified chlorosome envelope proteins into four motif families: CsmA/CsmE, $\mathrm{CsmB} / \mathrm{CsmF}$ (CsmH), $\mathrm{CsmC} / \mathrm{CsmD}(\mathrm{CsmH})$ and $\mathrm{CsmI} / \mathrm{Csm} / \mathrm{CsmX}$ (Li and Bryant, 2009). The high sequence similarity and functional relatedness of Csm proteins within their groups is indicative of a series of gene duplication events and subsequent divergence (Li and Bryant, 2009). Representatives of each of the four Csm groups were identified in the $C$-Ace metaproteome. Owing to the functional redundancy within Csm groups, the identified proteins may represent the full complement expressed in $C$-Ace.

RC complex is composed of two copies of the integral membrane protein PscA, one copy of the peripheral protein PscB, two copies of the cytochrome $c$ protein PscC and two copies of PscD (Hauska et al., 2001). PscA binds the primary electron donor P840, the primary electron acceptor $A_{0}$ and the FeS cluster, $F_{X}$, whereas PscB attaches to the two terminal FeS clusters, $\mathrm{F}_{\mathrm{A}}$ and $\mathrm{F}_{\mathrm{B}}$. Although PscB was not detected in the metaproteome, a pscB gene was identified in the metagenome data but was not part of the composite $C$-Ace genome assembly.

Our data indicate that $C$-Ace expresses the necessary chlorosome, FMO and RC proteins for cell viability and absorption of light energy for driving photosynthesis. The seasonal variation in light intensity at the depth where $C$-Ace dominates varies markedly $\left(0.01-10 \mu \mathrm{mol}\right.$ of photons $\left.\mathrm{m}^{2} \mathrm{~s}^{1}\right)$ (Burke and Burton, 1988b; Rankin et al., 1999). Short periods of relatively high light intensity (for example, $100 \mu \mathrm{mol}$ photon $\mathrm{m}^{2} \mathrm{~s}^{1}$ during ice melt out) 


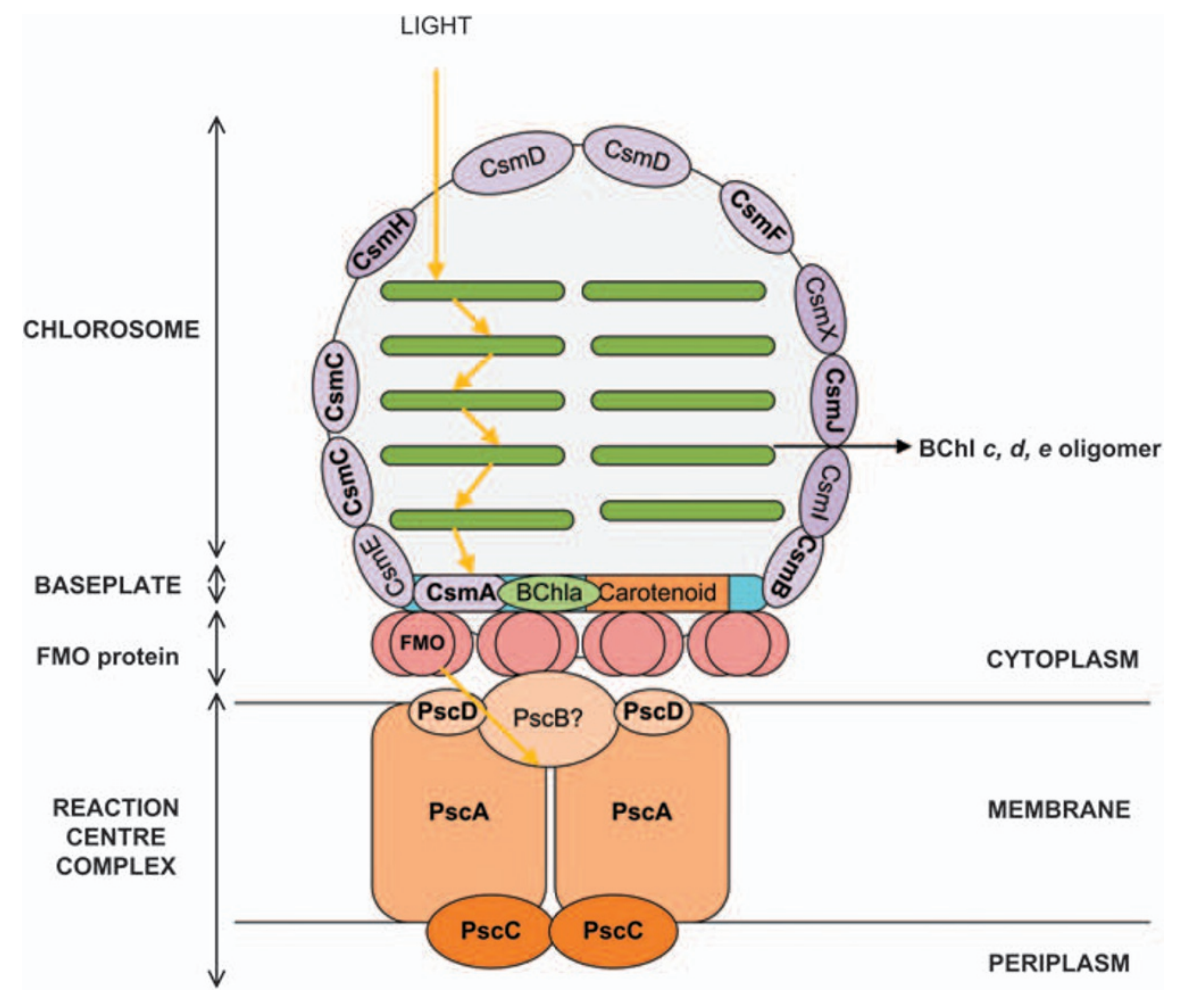

Figure 1 Photosynthetic apparatus. The photosynthetic unit comprises of the chlorosome containing the BChls encased in a monolipidprotein envelope, the Fenna-Matthews-Olson (FMO) protein and a reaction center (RC) complex. Proteins involved in chlorosome and envelop formation include CsmA, B, C, D, E, F, H, I, J and X. The BChls $c, d$ or $e$ are represented as rodlike structures absorbing light energy that gets funneled to the RC via the baseplate and FMO. The FMO protein is part of the photosynthetic apparatus and is organized as trimers and binds to BChl $a$ in the baseplate. The FMO and baseplate mediates the transfer of energy between the chlorosome and RC, which is found in the inner membrane. The core RC of the complex is composed of two copies of integral membrane proteins, PscA and one copy of the peripheral protein PscB, which carries the FeS centers. Two copies of PscC cytochrome $c$ proteins and one copy of PscD make up the rest of the RC complex. Proteins identified in the metaproteome are shown in bold. The diagram is adapted from Hauska et al. (2001) and Bryant and Frigaard (2006).

have also been recorded (Burke and Burton, 1988a,b). Clearly, it would be an advantage to be able to control the synthesis of the photosynthetic proteins (Morgan-Kiss et al., 2009), perhaps by increasing the ratio of BChl $c$ to BChl $a$ within the chlorosomes, as observed in other GSB as light intensity decreases (Borrego and Garcia-Gil, 1994; Borrego et al., 1999).

Isoprenoid, carotenoid and tetrapyrrole biosynthesis Important enzymes in the methylerythritol phosphate (MEP; Supplementary Figure S5), carotenoid biosynthesis (Figure 2) and tetrapyrrole synthesis pathways (Figure 3) were detected in the metaproteome, illustrating that these pathways are functioning to support the growth of $C$-Ace in the lake. The MEP pathway (also known as the non-mevalonate pathway) is used for the biosynthesis of isopentenyl diphosphate and dimethylallyl diphosphate (Supplementary Figure S5; Supplementary Table S3); a pathway that has been identified in some phototrophs (Hunter, 2007).

Carotenoid biosynthesis commences with the synthesis of phytoene, leading to the synthesis of chlorobactene and a group of minor carotenoids
(Figure 2). In addition to converting $\gamma$-carotene to chlorobactene, in brown-pigmented GSB, CruU converts $\beta$-isorenieratene to isorenieratene. $\beta$-Isorenieratene is generated from chlorobactene by $\mathrm{CruB}$ (Maresca et al., 2008). The $c r u B$ gene has been identified only in the genomes of isorenierateneproducing Chlorobium species (Maresca and Bryant, 2006). P. vibrioformis DSM 265 (green pigmented) encodes $c r u A$, but not $c r u B$. In the $C$-Ace genome, $c r u A$ was identified, but a blastp search for $c r u B$ from three isorenieratene-producing Chlorobium species revealed only matches to $c r u A$. Because the $C$-Ace genome is incomplete, it is not possible to determine if $c r u B$ is encoded, and therefore whether it has the capacity to produce the brown pigment isorenieratene. However, the overall similarity between the genomes of $C$-Ace and $P$. vibrioformis DSM 265 suggests it to be green pigmented.

Tetrapyrrole synthesis is essential for the generation of heme, bacteriochlorophyll (BChl), siroheme and vitamin $\mathrm{B}_{12}$ (Yaronskaya and Grimm, 2006). For $C$-Ace, a complete pathway was reconstructed that flows from glutamate metabolism to the synthesis of heme, siroheme, and BChl $a$ and $c$ (Figure 3). The activity of the BChU C-20 methyltransferase appears to determine the type of BChl accumulated in GSB, 


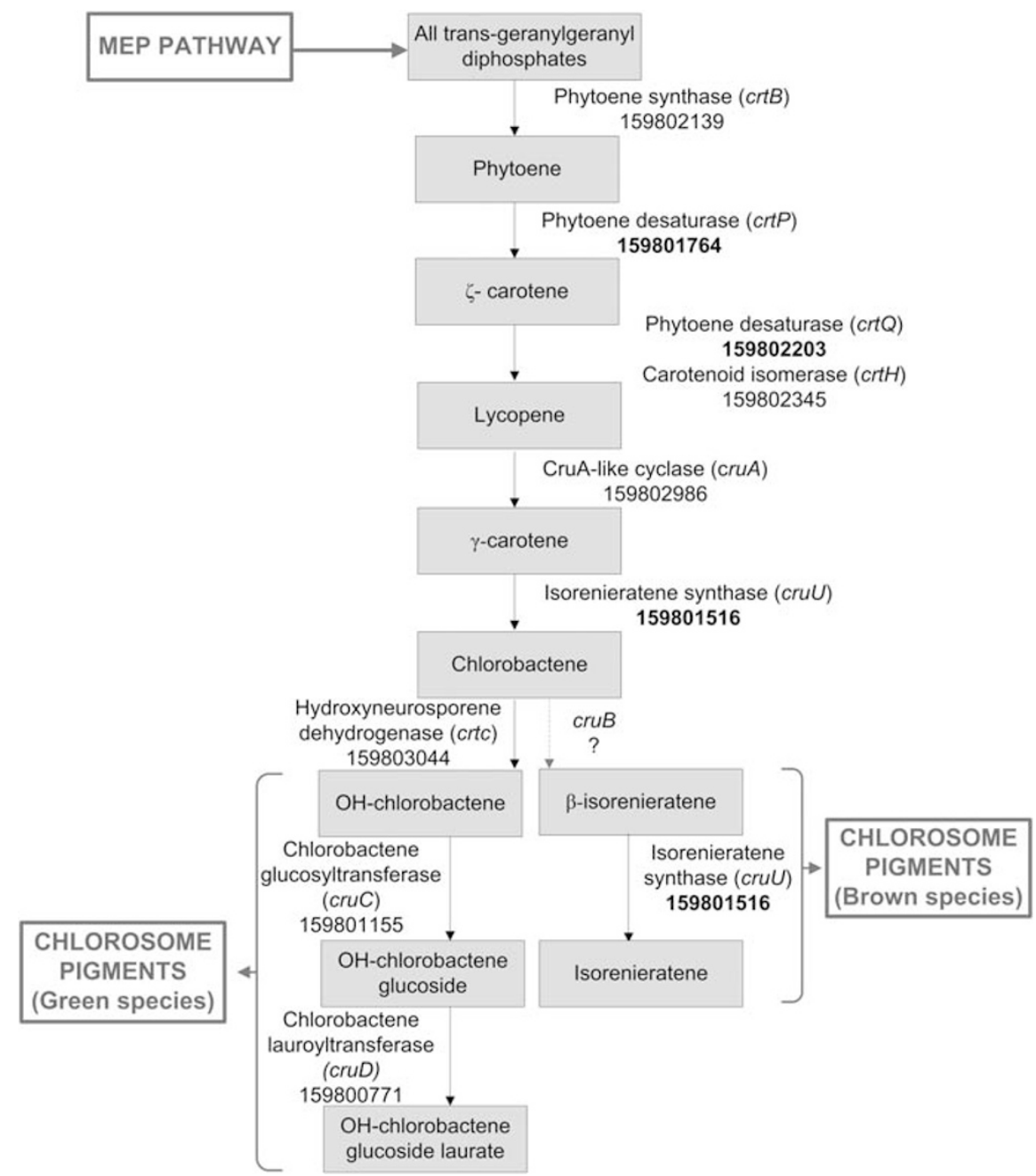

Figure 2 Pigment biosynthesis. Pathways for synthesis of green and brown pigments. Gene numbers corresponding to proteins detected in the metaproteome (bold font) or not detected (normal font) in the metaproteome but identified in the $C$-Ace metagenome are shown. Carotenoid biosynthesis is initiated by the condensation of two geranylgeranyl diphosphate $\left(\mathrm{C}_{20}\right)$ molecules to phytoene by phytoene synthase, CrtB (159802139) (Figure 2; Supplementary Table S3). Phytoene is converted by a series of desaturation, isomerization and cyclization steps to form $\gamma$-carotene, which is then converted to OH-chlorobactene by CrtU (159801516) and CrtC (159803044). CrtC, CruC (159801155) and CruD (15980077) are in turn collectively responsible for conversion of the major green pigment, chlorobactene to a group of minor carotenoids (Frigaard and Bryant, 2004; Maresca and Bryant, 2006).

and Chlorobium species unable to carry out this methylation have significantly reduced growth rates at low light intensities (Maresca et al., 2004). The identification of BChU in the metaproteome suggests that $C$-Ace produces BChl $c$. BChl $C$-producing strains of $C$. tepidum have been shown to grow faster at low light intensities $(8 \mu \mathrm{mol}$ of photons $\mathrm{m}^{2} \mathrm{~s}^{1}$ ) compared with isogenic BChl $d$ strains, and to be compromised at very high light intensities ( $>300 \mu \mathrm{mol}$ of photons $\mathrm{m}^{2} \mathrm{~s}^{1}$ ) (Maresca et al., 2004). In addition to being adapted to low light intensities, BChl $c$-producing strains of GSB are efficient in having an enhanced capacity to absorb light (wavelengths $350-850 \mathrm{~nm}$ ) in comparison with their BChl $d$-producing counterparts (Maresca et al., 2004). Red light $(\sim 700 \mathrm{~nm})$ is attenuated by the ice cover on Ace Lake whereas green light $(\sim 519 \mathrm{~nm})$ has the greatest penetration through the water column (Burch, 1988), which falls within the absorption spectra of BChl $c$. If $C$-Ace is a BChl $c$-producing strain (as our data indicate), the light conditions (wavelength and seasonal intensity) that are experienced at the $\mathrm{O}_{2}-\mathrm{H}_{2} \mathrm{~S}$ interface in Ace Lake are likely to suit the growth of the organism.

\section{Carbon dioxide fixation}

Typical of GSB (Buchanan and Arnon, 1990; Eisen et al., 2002), $C$-Ace appears to use the rTCA cycle for autotrophic fixation of $\mathrm{CO}_{2}$ (Figure 4). Although most enzymes are common to both the oxidative and the reductive TCA cycles, the latter requires key enzymes to catalyze irreversible steps: pyruvate ferredoxin oxidoreductase (PFOR) and 2-oxoglutarate ferredoxin oxidoreductase (OGFOR), and an 


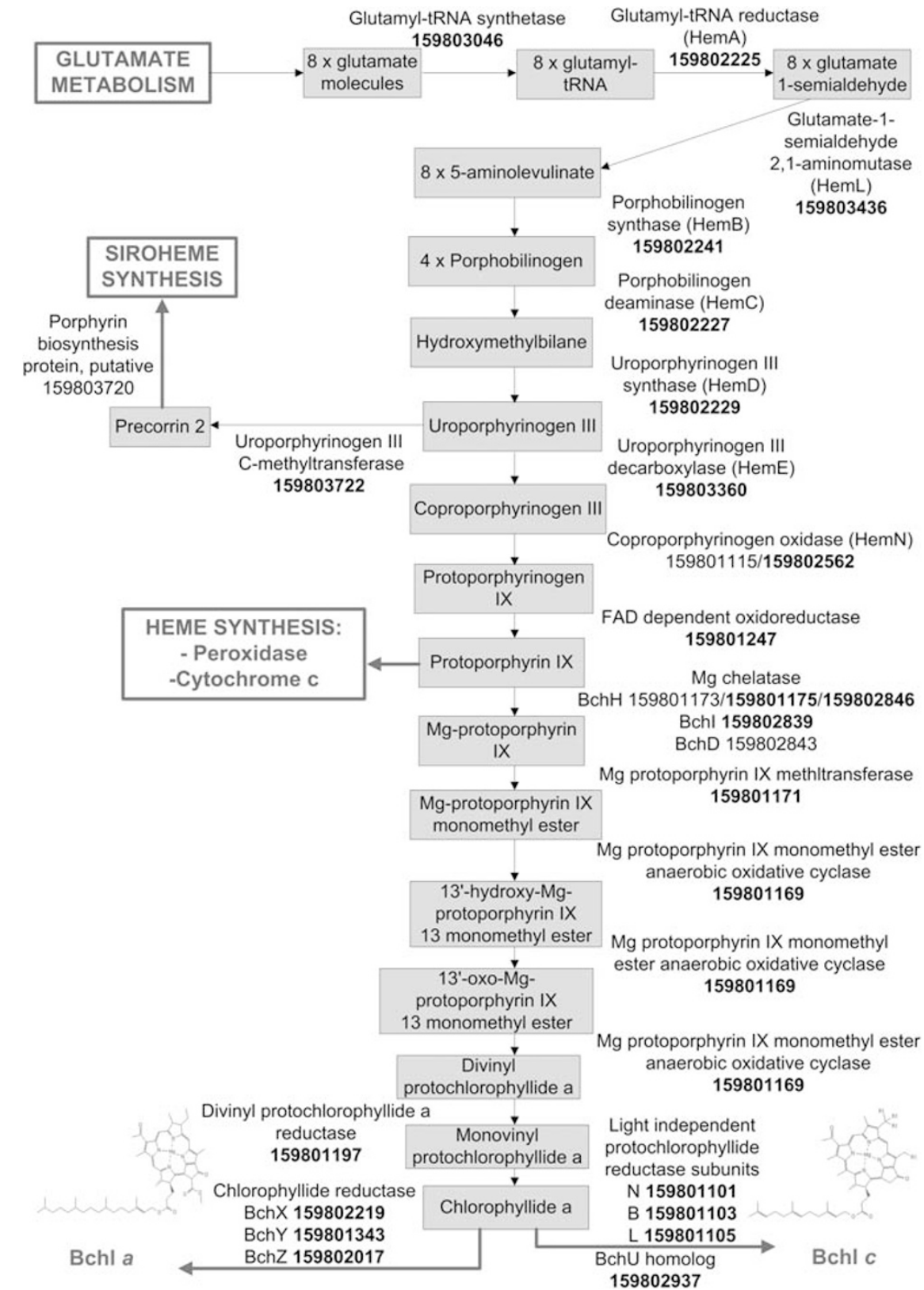

Figure 3 Bacteriochlorophyll biosynthesis. Pathway of bacteriochlorophyll $a / c$ biosynthesis and associated enzymes in $C$-Ace. Through a series of reactions, from glutamate and ATP, uroporphyrinogen III is synthesized. The fate of uroporphyrinogen III is then determined by two enzymes, uroporphyrinogen-III C-methyltransferase (159803722) and uroporphyrinogen decarboxylase, HemE (159803360). The methylation of uroporphyrinogen III by uroporphyrinogen-III C-methyltransferase enables the synthesis of siroheme, vitamin $\mathrm{B}_{12}$ and other coenzymes, whereas HemE feeds uroporphyrinogen III into a pathway for heme and BChl synthesis (Phillips et al., 2003). Protoporphyrin IX is the branch point for heme or BChl synthesis, with the BChl pathway requiring the incorporation of $\mathrm{Mg}^{2+}$ into protoporphyrin IX to produce Mg-protoporphyrin IX. BChU C-20 methyltransferase (159803570) directs Mg-protoporphyrin IX toward $\mathrm{BChl} C$ synthesis, while a series of alternative reductions generates chlorophyllide $a$ leading to BChl $c$ synthesis. Unlike the lightdependent protochlorophyllide oxidoreductase (POR) in cyanobacteria, protochlorophyllide is converted to chlorophyllide in green sulfur bacteria (GSB) by light-independent protochlorophyllide oxidoreductase (DPOR) (Gomez Maqueo Chew et al., 2007), a three subunit (BChB 159801103, BChN 159801101, BChl 159801105) enzyme complex. The light-independent reduction occurs in all anoxygenic photosynthetic bacteria enabling BChls to be synthesized irrespective of the presence of light (Fujita and Bauer, 2000).

ATP-dependent citrate lyase. All the enzymes are encoded in the $C$-Ace genome and most of the enzymes (or subunits thereof) for the rTCA cyclespecific and reversible reactions were detected in the metaproteome (Figure 4). 2-Oxoglutarate dehydrogenase was absent from the metagenome; this enzyme is not present in GSB (Overmann and Garcia-Pichel, 2006), and its absence from C-Ace is therefore unlikely to be an artifact of an incomplete genome. Thus, it is likely that $C$-Ace has a partial oxidative TCA cycle that provides 2-oxoglutarate for ammonia assimilation. The detection of citrate 


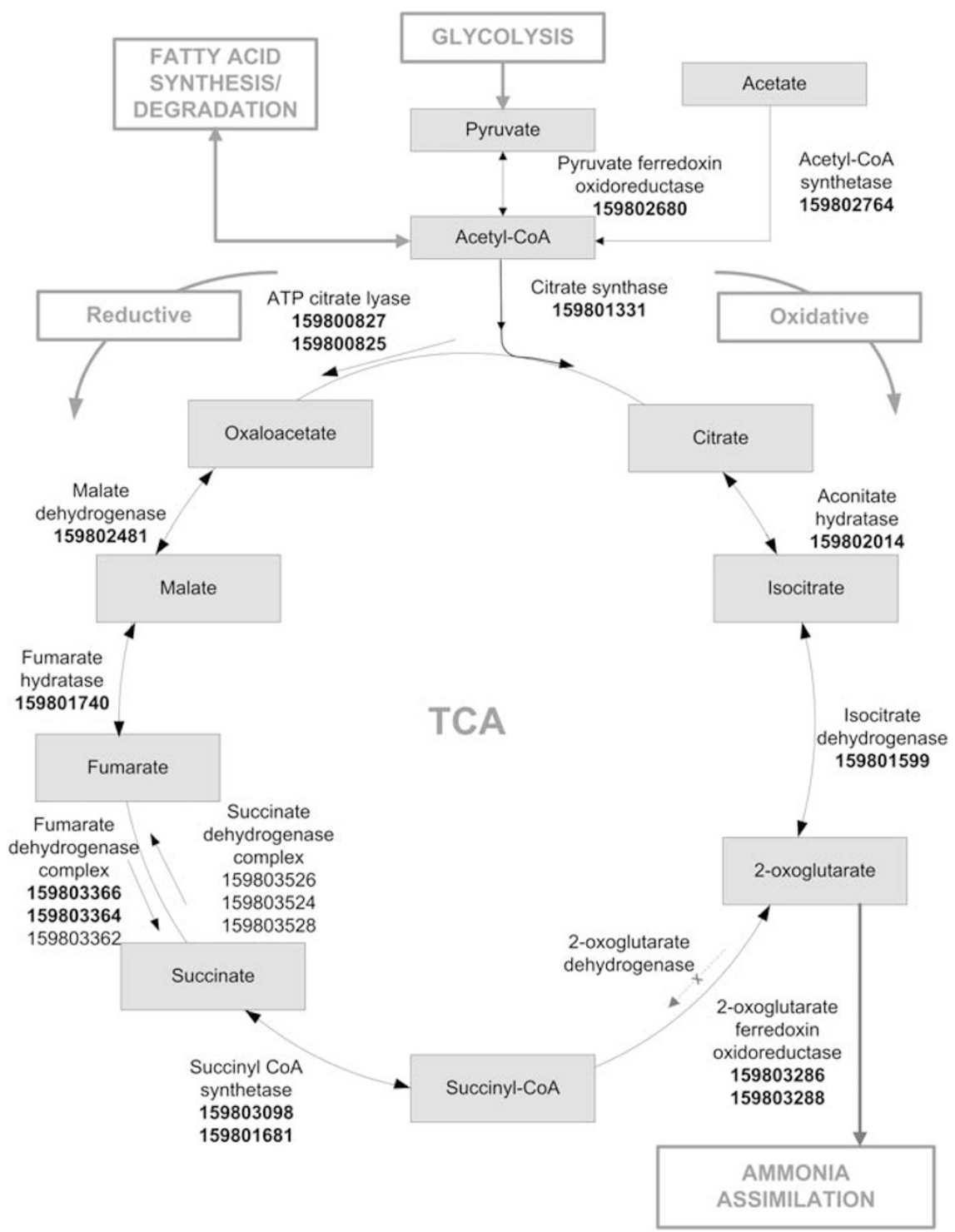

Figure 4 Tricarboxylic acid (TCA) cycle. Partial oxidative and complete reductive TCA cycles in $C$-Ace.

synthase (159801331) and ATP-citrate lyase (subunits 159800827 and 159800825) indicates that the TCA cycle is operating in both the reductive and the oxidative directions, for carbon fixation and ammonia assimilation, respectively. Generation of the essential precursor 2-oxoglutarate by the oxidative pathway requires fewer steps and no ATP compared with the reductive direction. The operation of a full circuit of the rTCA cycle alongside a partial oxidative cycle may indicate that $C$-Ace has sufficient regulatory capacity to avoid futile cycling of carbon flow.

Glycolysis, gluconeogenesis and acetate assimilation Glycolytic and gluconeogenic pathways were identified in C-Ace (Supplementary Figure S6). Acetyl CoA generated from the rTCA cycle or by activation of exogenous acetate by acetyl-CoA synthetase
(159802764) can be reductively carboxylated to pyruvate by PFOR (159802680). The ability to assimilate simple organic carbon compounds such as acetate is advantageous for GSB when growth is impeded by limiting electron-donating substrates (for example, sulfide, thiosulfate) (Overmann and Garcia-Pichel, 2006). Cell yield has been shown to triple when acetate is provided as an additional carbon source in sulfide- and thiosulfate-limited conditions (Overmann and Pfennig, 1989). Decomposition of organic matter by microbial activity in Ace Lake is likely to provide acetate as an additional carbon source for $C$-Ace (Franzmann et al., 1991b). The availability of acetate as an additional carbon source to $\mathrm{CO}_{2}$ would enable increased biomass formation when conditions are suitable for phototrophic growth. The number of photosynthetic GSB in Ace Lake is lowest in winter (May-August) and highest in summer (December-January: $6 \times 10^{7}$ cells $\mathrm{ml}^{-1}$ ), and 
the capacity of $C$-Ace to reach high cell numbers during periods of optimal light conditions is likely to assist survival through the winter months (Burke and Burton, 1988b; Rankin et al., 1999). As C-Ace cannot proliferate without light, cells could be more vulnerable during the winter period to lysis and grazing.

\section{Storage and metabolism of organic carbon}

A trehalose synthase (159803420) and an ADPglucose type glycogen synthase (159801111) were identified in the metaproteome (Supplementary Table S3), illustrating a capacity to synthesize storage material. Accumulation of trehalose can promote salt tolerance (Makihara et al., 2005) and cryoprotection. Members of the Chlorobiaceae grow under a range of hypersaline conditions, and the synthesis of trehalose by the enzyme trehalose synthase in $C$-Ace may provide a mechanism for osmoprotection in response to the high salt gradient at the chemocline $\left(20-30 \mathrm{gl}^{-1}\right)$, in addition to serving as storage material. Under conditions of nutrient imbalance, when carbon substrates and light energy are in excess, but nitrogen and phosphorus substrates are limiting, GSB synthesize glycogen, which is accumulated intracellularly (Overmann, 2006). The data for $C$-Ace are consistent with phototrophic growth in summer leading to the synthesis of glucose and complex sugars. Polymers such as glycogen could be broken down during dark periods (including during the winter months), and serve as a source of energy for cell maintenance. However, these would be unable to serve as a carbon reserve in the dark because the byproducts cannot be re-assimilated without light (Mas and Van Gemerden, 1995). Polymer-degrading enzymes, $\alpha$ amylases $(159803024,159803422)$ and an $\alpha$-glucan phosphorylase (159802594), were also detected in the metaproteome (Supplementary Table S3). The identification of enzymes involved in both polyglucose storage and breakdown might reflect conditions of sulfide flux. Efficient oxidation of sulfide by GSB during summer (see Sulfur cycling) may cause local depletion of this substrate. Under such conditions it is likely that carbon would be stored as glycogen. When sulfide becomes available from SRB, C-Ace accesses its polyglucose reserves to generate biomass. Oligotrophic marine bacteria have evolved enhanced capacities to generate storage material, compared with copiotrophs (Lauro et al., 2009). Some species (for example, heterotrophic Sphingopyxis alaskensis) use storage pathways even when simpler forms of metabolizable carbon sources are available (Willams et al., 2009). Similar to other GSB (Lauro et al., 2009), $C$-Ace has genomic signatures of an oligotroph.

$C$-Ace has limited capabilities for the assimilation of organic compounds, which is consistent with other GSB (Eisen et al., 2002). Thus, the partial phosphotransferase system consisting of enzyme I
(159803242), enzyme IIA (159803172) and an HPr kinase (Supplementary Table S3) is likely to serve a regulatory function in nitrogen and carbon metabolism, rather than in transport (Eisen et al., 2002; Commichau et al., 2006).

Collectively, these data indicate that in the nutrient-restricted lake environment, $C$-Ace has a system for gluconeogenesis and glycogen synthesis that can rely on $\mathrm{CO}_{2}$ and acetate assimilation to synthesize glucose and store glycogen/starch reserves to facilitate growth when they are needed. In addition, trehalose synthesis may facilitate salt adaptation.

\section{Pentose phosphate pathway}

Ribose sugars (for nucleotide synthesis) and reducing power (NADPH) are generated by the pentose phosphate pathway. Although a complete set of genes are present in C-Ace (Supplementary Figure S7), the only enzyme involved in the oxidative steps that was identified in the metaproteome was glucose 6-phosphate dehydrogenase (159801277). In contrast, all the enzymes in the nonoxidative steps of the pentose phosphate pathway were identified in the metaproteome.

\section{Fatty acid biosynthesis}

A fatty acid biosynthesis ( $f a b)$ gene cluster consisting of $f a b F$, an acyl carrier protein (ACP), fabG, fabD, fabH and plsX (Heath and Rock, 2002; Mansilla et al., 2004) is encoded and expressed in C-Ace (Supplementary Figure S8); only the ACP (159803296) was not detected in the metaproteome.

The first step in the anaerobic biosynthesis of straight/saturated chain fatty acids is the conversion of acetyl CoA to malonyl-CoA, catalyzed by a $\mathrm{Mn}^{2+}$ requiring acetyl-CoA carboxylase complex (Supplementary Figure S8). The initiation of fatty acid biosynthesis begins with the transfer of malonate group on malonyl-CoA to the ACP (159802037) by $S$-malonyltransferase (FabD-159802045). 3-OxoacylACP synthase III (FabH-159802049) catalyzes a condensation reaction between acetyl-CoA and malonyl-ACP to form a four-carbon, acetoacetylACP with the loss of $\mathrm{CO}_{2}$. The acetoacetyl-ACP proceeds through a cycle of chain elongation steps involving the addition of a two-carbon unit from malonyl-ACP to the growing acetyl-ACP molecule by 3-oxoacyl-ACP synthase II (FabF-159802033); the 3-oxoacyl-ACP synthase I, $f a b B$ gene that can also perform the same condensation reaction was not detected in the metagenome. Subsequently, ketoester formation ( $f a b G$ - 159802041), water removal ( $f a b Z-$ 159802776) and formation of a saturated acyl-ACP ( fabI-159801595) enables further condensation reactions to occur.

The mechanism for unsaturated fatty acid synthesis in GSB is not yet known. In contrast to the highly conserved nature of the rest of the fatty acid synthesis pathway across bacteria, the enzyme 
responsible for insertion of the cis double bond of unsaturated fatty acids is highly variable, and has yet to be identified in many anaerobic bacteria. GSB lack FabA, and it is not known if FabZ (a homologue of FabA) can serve as an isomerase as well as a dehydratase in GSB. FabF is likely to regulate the balance of monounsaturated versus saturated fatty acid products in $C$-Ace, as it does in Escherichia coli after a downshift in growth temperature (de Mendoza et al., 1992). At low temperature, an increased rate of synthesis and accumulation of unsaturated 18:1 $\Delta 9$ (cis-vaccenic acid) has been observed in E. coli (de Mendoza et al., 1992). FabF is responsible for the elongation of $16: 1 \Delta 9$ (palmitoleic acid) over saturated fatty acids 16:0 (palmitic acid), and directs substrates toward the synthesis of $18: 1 \Delta 9$ in response to a reduction in temperature (de Mendoza et al., 1992; Russell, 2008). Fatty acid analysis of particulate matter in Ace Lake identified the straight chain saturated 16:0 and monounsaturated 16:1 $\Delta 9$ fatty acids as the most abundant at depths where $C$-Ace predominates (Volkman et al., 1988). Other lower abundance fatty acids included 18:1 $\Delta 9$, 18:0, 14:0 and 15:0. Chlorobium species have been attributed to producing the 16:0,16:1 $\Delta 9$ and 14:0 fatty acids (Volkman et al., 1988).

Overall, the metaproteomic data for $C$-Ace are consistent with FabF performing a key role in the in situ synthesis of monounsaturated fatty acids, and $C$-Ace contributing to the abundant fatty acid signatures detected in Ace Lake. The synthesis of unsaturated fatty acids by $C$-Ace is also consistent with the role that unsaturated fatty acids have in enhancing membrane fluidity at low temperatures; a physiological adaptation common in cold-adapted microorganisms (Russell, 2008). Lipid analysis of thermophilic $C$. tepidum detected predominantly saturated fatty acids and low quantities of unsaturated fatty acids (Sørensen et al., 2007).

\section{Ammonia assimilation}

With the carbon skeleton provided by 2-oxoglutarate, ammonia/ammonium is assimilated into two central nitrogen intermediates, glutamate and glutamine, which serve as nitrogen donors for the cell's entire biosynthetic needs (Supplementary Figure S9). The ammonia concentration measured in Ace Lake at the depth where $C$-Ace resides (and deeper) was 50-55 $\mu \mathrm{M}$, at least 10-fold higher than that of nitrate and nitrite (Burton, 1980). Both glutamine synthetase (159802199) and glutamate synthase $(59801694,159802974,159801691)$ were represented in the metaproteomic data (Supplementary Figure S9; Supplementary Table S3). Enzymes required for the fixation of dinitrogen or the assimilation of nitrate were present in the metagenome, but absent from the metaproteomic data (Supplementary Table S3). The data suggest that at the time of sampling $C$-Ace derived its nitrogen from ammonia, a preferred nitrogen source, and would proceed through the ATP-dependent glutamine synthetase/glutamate synthase pathway (Supplementary Figure S9), the preferred pathway under conditions of low ammonia concentration.

\section{Sulfur cycling}

Sulfur-oxidizing GSB require light as the energy source, with hydrogen sulfide $\left(\mathrm{H}_{2} \mathrm{~S}\right)$, elemental sulfur and thiosulfate among potential electron donors for the reduction of $\mathrm{CO}_{2}$. The ability to use thiosulfate as an electron donor is not found in all GSB, and in the absence of a Sox cluster (soxXY$Z A B W$ ) in the metagenome data, this may also be the case in $C$-Ace. A pathway for sulfide oxidation was defined for $C$-Ace with many of the relevant proteins detected in the metaproteome (Figure 5 enlarged inset of sulfur cycle; Supplementary Table S3). Sulfide-quinone reductase, SQR (159803450), oxidizes sulfide to zero-valent sulfur, which is released as a soluble polysulfide chain (Griesbeck et al., 2002). Flavocytochrome $c$, FccAB (159803630, 159803632), was also detected; as an alternative mechanism for sulfide oxidation to sulfur, its role in GSB is unclear (Frigaard and Bryant, 2008). The presence of SQR and FCcAB in the $C$-Ace metaproteome indicates that both are relevant to sulfide oxidation in Ace Lake, and may contribute to the depletion of this reduced sulfur species from the depth at which $C$-Ace grows (see Storage and metabolism of organic carbon). The dissimilatory sulfite reductase system, DsrNCABLEEFHTMKJOP (159803690-159803718) catalyzes the subsequent conversion of sulfur to sulfite. The most likely candidate for the final oxidation of sulfite to sulfate is a polysulfide-reductase-like complex 3 (159803444, 159803446, 159803448). A sulfate permease, SulB (159802643), is likely to be used to export sulfate produced by the cell, making it available as an electron acceptor for sulfate reduction by SRB. Similar to most GSB, there is no evidence for assimilatory sulfate reduction in $C$-Ace, emphasizing its strict dependence on $\mathrm{H}_{2} \mathrm{~S}$ generated by SRB. A number of other proteins, whose roles in sulfur metabolism are not clear, were identified in the metaproteome or metagenome, including heterodisulfide reductase subunits AB (159800421, 159800423) and a molybdenum-containing protein (159803678) related to polysulfide reductase (Supplementary Table S3).

The $\mathrm{H}_{2} \mathrm{~S}$ concentration in Ace Lake (December 1987) increases from $0-1 \mathrm{~mm}$ at the depth where $C$-Ace grows, to $8 \mathrm{mM}$ at the deepest point of the lake (Rankin et al., 1999). In contrast, sulfate is undetectable at maximum depth, increases to a peak of $9 \mathrm{mM}$ at a depth immediately below the chemocline and decreases to $3 \mathrm{mM}$ at the surface of the lake. These data are consistent with $\mathrm{H}_{2} \mathrm{~S}$ released by SRB in the anoxic zones diffusing up the water column and sulfide being fully used by $C$-Ace (and other GSB). The production of sulfate by $C$-Ace would in turn provide a continuous cycling of sulfur 


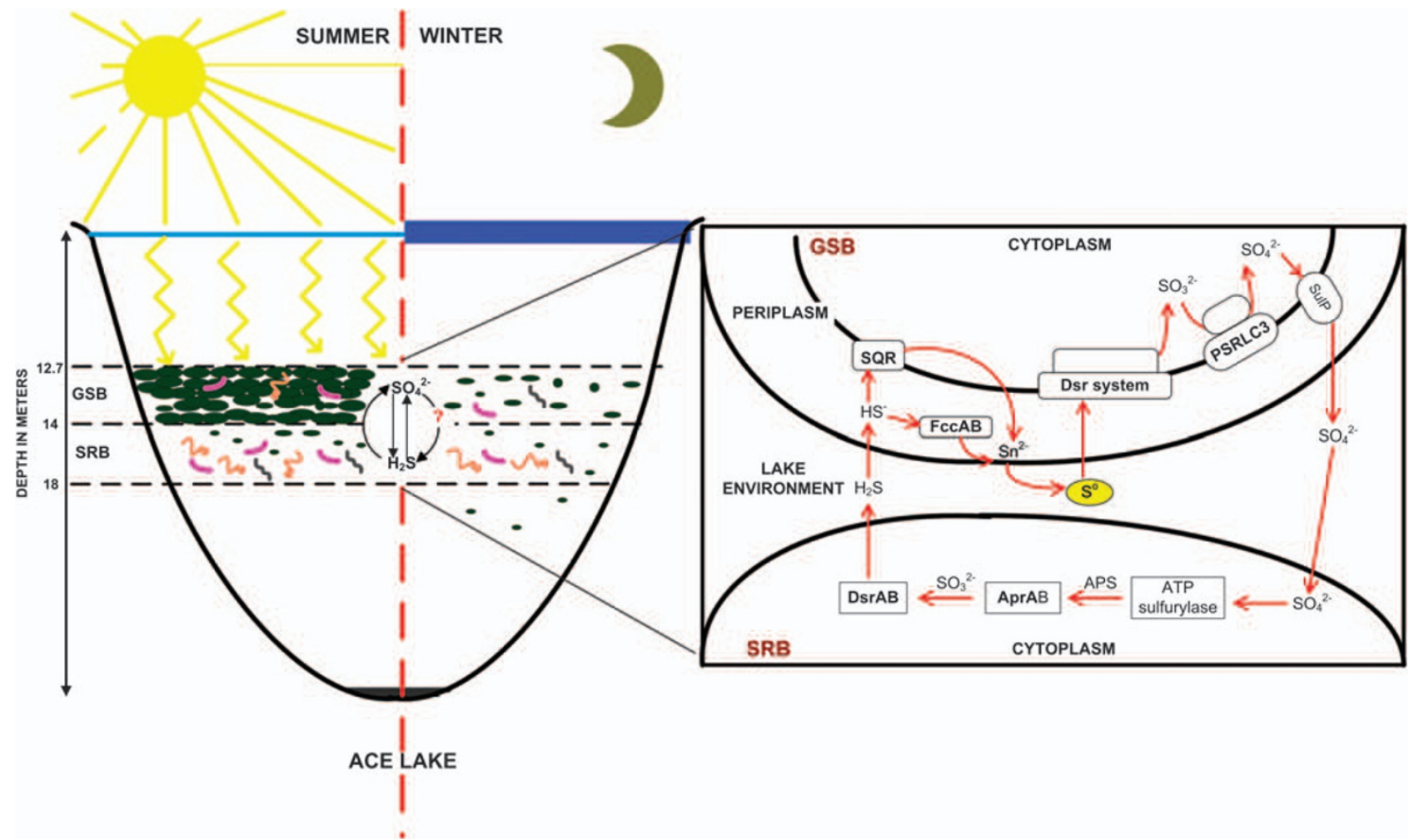

Figure 5 Sulfur cycle. Sulfur cycle for $C$-Ace and sulfate-reducing bacteria (SRB) within Ace Lake. Sulfide in the form of $\mathrm{H}_{2} \mathrm{~S}$ is generated by the community of SRB residing in the anoxic zone of the lake (below $12.7 \mathrm{~m}$ ). The exchange of sulfur between the green sulfur bacteria (GSB) and SRB is shown in the inset. During summer, the thick zone of $C$-Ace just below the chemocline (12 m) oxidizes the sulfide produced from the SRB to sulfate. Sulfate then diffuses to neighboring SRB in the zone and down the water column, whereupon it is reduced back to sulfide. The extent of light penetration in summer versus winter is shown, with phototrophic energy generation and cell growth occurring during the summer months. Enzymes identified in the metaproteome are shown in the inset.

compounds between the GSB and the SRB in the lake (Figure 5). Support for this was further obtained from metaproteomic analysis of biomass collected from the $14 \mathrm{~m}$ zone directly below the $12.7 \mathrm{~m}$ zone of $C$-Ace. Enzymes used by SRB in sulfate reduction that were identified included an adenylylsulfate reductase, AprA subunit, and a dissimilatory sulfite reductase enzyme, DsrA and B subunit (Supplementary Table S3). Preliminary metagenomic analysis of data derived from the $3 \mu \mathrm{m}$ membrane fraction of the $12.7 \mathrm{~m}$ zone also revealed the presence of SRB, indicating that the SRB coexist with the GSB. These SRB had a high proportion of genes involved in motility, chemotaxis and degradation of chlorinated aromatic compounds, indicating the SRB can use recalcitrant compounds (possibly deposited as the remains of zooplankton and phytoplankton from the upper aerobic zone) as a carbon source while cycling sulfate to sulfide.

\section{Oxidative stress}

The dissolved $\mathrm{O}_{2}$ concentration measured at the time of sampling was $\sim 0.4 \mathrm{mM}$ at the surface and $\sim 0.2 \mathrm{mM}$ at the $12.7 \mathrm{~m}$ sampling depth (data not shown). Owing to its position near the steep oxycline in the lake, and its obligate anaerobic metabolism, $C$-Ace may be prone to oxidative stress by reactive oxygen species generated as a result of the low potential of electron transfers typical of anaerobes (Imlay, 2003). Several oxidative stress proteins that may fulfill roles in oxidative defense were identified in the metaproteome (Supplementary Table S3): a superoxide dismutase (159801535), catalase-peroxidase/hydroperoxidase I (159801779), alkyl hydroperoxide reductase (159802085), thiol peroxidase (159802716), thioredoxins (159801715, 159801555) and thioredoxin reductase (159801713). A number of $C$-Ace proteins contain $\mathrm{FeS}$ clusters (for example, chlorosome RC, coenzymes, bacteriochlorophylls), which are extremely sensitive to attack by the superoxide radical, $\mathrm{O}_{2}^{-}$. The removal of $\mathrm{O}_{2}^{-}$is catalyzed by superoxide dismutase enzymes through the dismutation of $\mathrm{O}_{2}^{-}$to hydrogen peroxide, $\mathrm{H}_{2} \mathrm{O}_{2} . \mathrm{H}_{2} \mathrm{O}_{2}$ is still potentially toxic to the cell and can be converted to $\mathrm{H}_{2} \mathrm{O}$ and $\mathrm{O}_{2}$ by catalaseperoxidase/hydroperoxidase I. Alkyl hydroperoxide reductase, thiol peroxidase and thioredoxins are able to reduce other organic hydroperoxides and may also catalyze the conversion of $\mathrm{H}_{2} \mathrm{O}_{2}$ (Farr and Kogoma, 1991; Li et al., 2009). Alkyl hydroperoxide reductase has also been shown to scavenge endogenous $\mathrm{H}_{2} \mathrm{O}_{2}$ ( $\mathrm{Li}$ et al., 2009). In C. tepidum, chlorobactene has also been shown to function as a 
photoprotectant, and specific quinones within the chlorosome have an even larger role in providing a mechanism to quench the excited states of chlorosomes (on exposure to light and $\mathrm{O}_{2}$ ) preventing the production of singlet oxygen species (Frigaard and Bryant, 2006; Kim et al., 2007; Li et al., 2009). Similar mechanisms may be used by $C$-Ace to counter oxidative damage if cells are exposed to $\mathrm{O}_{2}$ during summer.

\section{Genes that do not match known GSB}

Among the 71 genes that were assigned to phyla distinct from GSB in the Chlorobiaceae family (Supplementary Figure S1; Supplementary Table S2), a number of them provided clues about possible mechanisms of adaptation. In $C$-Ace, six genes were predicted to be involved in capsular polysaccharide formation and lipopolysaccharide production: putative capsular polysaccharide biosynthesis protein, mannose-1-phosphate guanylyltransferase, UDP$\mathrm{N}$-acetylglucosamine 2-epimerase, UDP- $\mathrm{N}$-acetylD-mannosamine dehydrogenase, GDP-mannose 4,6dehydratase and a putative glycosyltransferase (genes 169800457, 159800859, 159800861, 159800863, 159800461 and 159800467 in Supplementary Table S2). The presence of these genes may indicate a requirement for polysaccharide structures distinct from other known members of the Chlorobiaceae as a mechanism for achieving cold adaptation. Genome evolution through lateral gene transfer was reported to be important for cold adaptation of Methanococcoides burtonii; a methanogen isolated from the bottom waters of Ace Lake (Allen et al., 2009). Consistent with the analysis of the $C$-Ace genome, the acquisition of polysaccharide biosynthesis genes by lateral gene transfer was linked to the ability of $M$. burtonii to grow at low temperature (Allen et al., 2009).

Genes encoding the three subunits (M, S and R) of a type I DNA restriction and modification (RM) system were arranged in $C$-Ace genome in the order: subunit R (159800462), subunit S (159800469), a gene with a DNA-binding domain (159800473) and subunit M (159800475). In addition, two copies of a res gene (159801046 and 159802022), belonging to one of the two subunits (Res and Mod) of a type III restriction enzyme complex were present in the genome. One possibility is that these defense mechanisms help protect $C$-Ace against bacteriophage attack over the dark winter period, when cell replication has effectively ceased. An ABC transporter for the uptake of iron was also encoded in the $C$-Ace genome (159802314, 159802318, 159802322). The ability to import iron is essential for the synthesis of heme groups and the Fe-S clusters of RCs of the light-harvesting units in GSB. Another gene encoding the periplasmic component of an ABC transporter (159802310) involved in nitrate/ sulfonate/bicarbonate uptake was also identified. In the $M$. burtonii genome, the Defence mechanisms
COG category was overrepresented compared to genomes from archaeal thermophiles and hyperthermophiles (Allen et al., 2009). The individual COGs were mainly from type I RM systems, and specific ABC transporters. The presence of specific polysaccharide biosynthesis, RM system and ABC transporter genes in $C$-Ace and $M$. burtonii, is consistent with them having a role in cold adaptation in both archaea and bacteria, and argues for further experimental work to be performed to test these inferences.

\section{Conclusion}

The ability to perform metaproteomics with matching metagenome data for an environmental community consisting largely of a single GSB, $C$-Ace, has allowed us to construct a working model describing the protein complement required for thriving under cold, nutrient- and $\mathrm{O}_{2}$-limited, and extreme light conditions (Figure 6). The success of GSB has been attributed to the extremely efficient light capturing abilities of the chlorosomes, which allows growth at extremely low light intensities, and (for those GSB that have a Dsr system) the efficient and complete oxidation of sulfur (Frigaard and Bryant, 2006, 2008). The survival strategy for $C$-Ace during the winter months depends on building up sufficient biomass to remain viable during winter and re-commence growth when sufficient light resumes later in the season. Although this capacity has been inferred (Burke and Burton, 1988a,b), the pathways that facilitate an obligate phototrophic metabolism of GSB, mixotrophic assimilation of simple carbon compounds and sulfide oxidation in Antarctic GSB have been mapped out for the first time, in $C$-Ace.

We regard the metabolic simplicity of $C$-Ace as an asset for dealing with an environment as challenging as Ace Lake: nutrient-depleted (oligotrophic) conditions with minimal light, little or no $\mathrm{O}_{2}$, but available $\mathrm{H}_{2} \mathrm{~S}$. Metabolic conservatism is a hallmark of an oligotrophic physiology (Lauro et al., 2009), and $C$-Ace can generate biomass from a narrow pool of ubiquitous substrates (for example, $\mathrm{CO}_{2}$, acetate, pyruvate). The metabolic efficiency is further underscored by having $\mathrm{CO}_{2}$ fixation and the generation of the carbon skeleton for amino-acid biosynthesis being served by a single pathway that can be turned in either reductive or oxidative directions. The rTCA cycle for carbon assimilation has been considered the primordial pathway for $\mathrm{CO}_{2}$ fixation, and to have its origins in anaerobic environments rich in $\mathrm{H}_{2} \mathrm{~S}$ (Wächtershäuser, 1990). The metaproteome data for $C$-Ace also indicate that although the 2-oxoglutarate necessary for ammonia assimilation could be obtained from the rTCA cycle (Overmann, 2006), this precursor can be generated through the less energy-intensive oxidative route.

This study identified traits that are likely to be specifically important for adaptation to the cold and the proliferation of C-Ace in Ace Lake. This 


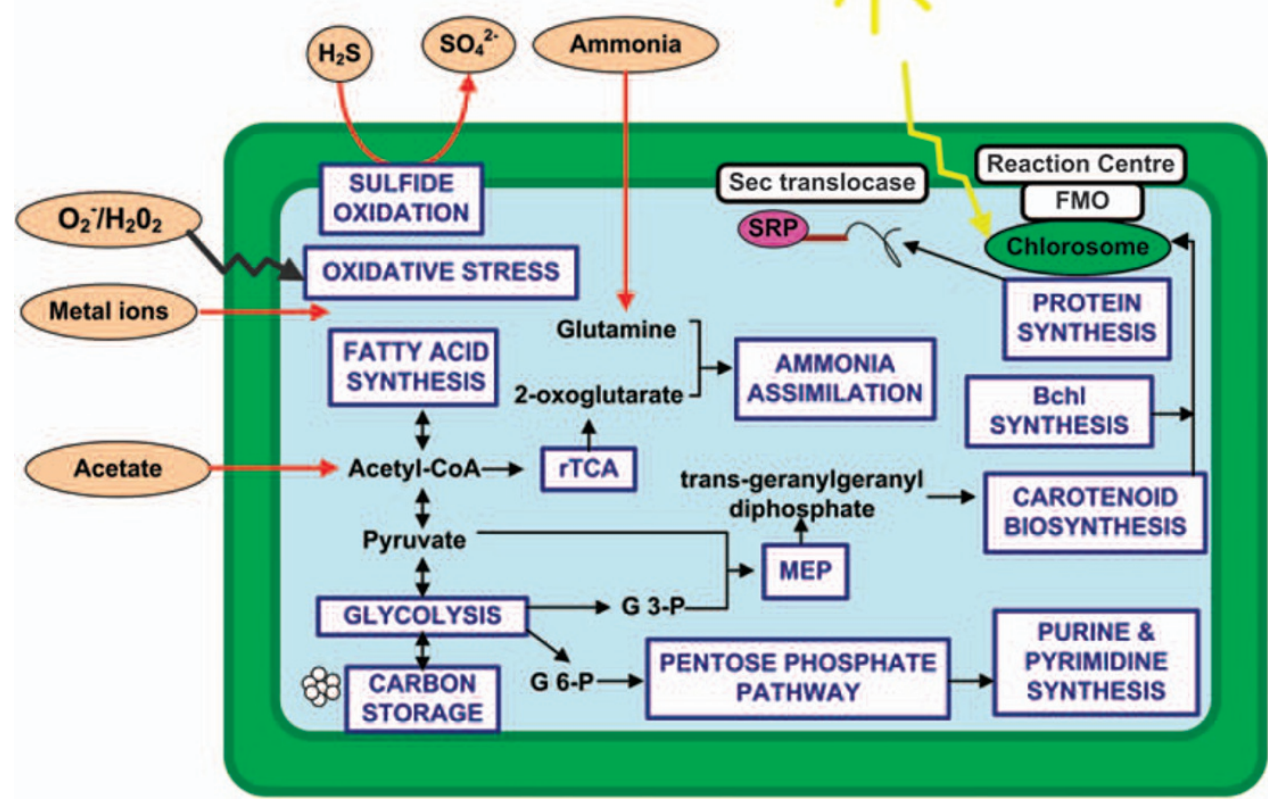

Figure 6 Overview of the biology of $C$-Ace. Cellular pathways defined from metaproteogenomic analysis. Major metabolic pathways (blue text in boxes), substrates acquired from the lake environment (red arrows), biological processes within the cell (black arrows), influx light and adsorption by the chlorosome (yellow arrow), and oxidative stress by reactive oxygen species (gray arrow) are shown.

included proteins involved in DNA processing, nucleic acid binding and folding/refolding of proteins at low temperature. Analysis of the lipid biosynthesis pathways, and particularly the synthesis of FabF, shows that cold adaptation in $C$-Ace is likely to be mediated by the synthesis of monounsaturated fatty acids to facilitate the maintenance of membrane fluidity at low temperatures. Cold adaptation also appears to have involved the acquisition of specific polysaccharide biosynthesis genes, RM systems and certain ABC transporters.

The stable stratification of Ace Lake and the biotic and abiotic conditions prevailing at the chemocline have not only selected for a very low complexity community, but have enabled a high-density population to develop; turbidity in this zone is far greater than anywhere else in the water column (Rankin et al., 1999; Coolen et al., 2006). The capacity for a single genotype to rise to such dominance while the ecosystem sustains the growth of distinct populations in the water column above and below highlights the evolutionary specialization that can occur in an otherwise physically continuous aquatic system. To achieve this, $C$-Ace has evolved physiological traits that promote its ability to compete very effectively with other GSB and gain dominance, while evolving a syntrophic relationship with SRB that relies on the exchange of sulfur compounds with neighbors within proximity and deeper into the anaerobic zone. $C$-Ace also appears to possess oxidative stress response mechanisms capable of protecting against damaging oxygen species that may occur due to its proximity to the aerobic zone.

The study provides solid foundation for comparative studies of GSB in other Antarctic lakes (for example, Clear, McCallum, Abraxas, Pendant, Burton, Fletcher) and marine basins (for example, Ellis Fjord, Taynaya Bay), where populations are reported to be abundant (Burke and Burton, 1988b). These different systems vary in geochemical and physical properties (for example, salinity, depth, temperature, light quality, reduced sulfur compounds) (Burke and Burton, 1988a,b). Extending comparisons to low light-adapted, marine GSB, such as those found at the chemocline of the Black Sea (Manske et al., 2005) or near a deep-sea hydrothermal vent (Beatty et al., 2005), will help establish how GSB have evolved in response to important global ecological factors.

\section{Acknowledgements}

We thank John Bowman, Louise (Cromer) Newman, Anthony Hull, John Rich and Martin Riddle in providing helpful discussion and logistical support associated with the Antarctic expedition. Special thanks to Karla Heidelberg for genuine assistance in initiating genome sequencing and for assistance with sampling design, and Ken Nealson for critically reviewing the paper. We also thank the reviewers for very insightful comments. The work of the Australian contingent was supported by the Australian Research Council and the Australian Antarctic 
Division. Mass spectrometric results were obtained at the Bioanalytical Mass Spectrometry Facility within the Analytical Centre of the University of New South Wales. This work was undertaken using infrastructure provided by NSW Government co-investment in the National Collaborative Research Infrastructure Scheme. Subsidized access to this facility is gratefully acknowledged. The work of JCVI members was supported by funding provided from the Gordon and Betty Moore Foundation.

\section{References}

Allen MA, Lauro FM, Wiliams TJ, Burg D, Siddiqui KS, De Francisci D et al. (2009). The genome sequence of the psychrophilic archaeon, Methanococcoides burtonii: the role of genome evolution in cold adaptation. ISME J 3: 1012-1035.

Beatty JT, Overmann J, Lince MT, Manske AK, Lang AS, Blankenship RE et al. (2005). An obligately photosynthetic bacterial anaerobe from a deep-sea hydrothermal vent. Proc Natl Acad Sci USA 102: 9306-9310.

Biebl H, Pfennig N. (1978). Growth yields of green sulfur bacteria in mixed cultures with sulfur and sulfate reducing bacteria. Arch Microbiol 117: 9-16.

Blankenship RE, Olson JM, Miller M. (1995). Antenna complexes from green sulfur bacteria. In Blankenship RE, Madigan MT, Bauer CE (eds). Anoxygenic Photosynthetic Bacteria. Kluwer: Dordrecht, The Netherlands, pp 399-435.

Blum H, Beier H, Gross HJ. (1987). Silver staining of proteins in polyacrylamide gels. Electrophoresis 8: 93-99.

Borrego CM, Garcia-Gil LJ. (1994). Rearrangement of light harvesting bacteriochlorophyll homologs as a response of green sulfur bacteria to low light intensities. Photosynth Res 45: 21-30.

Borrego CM, Gerola PD, Miller M, Cox RP. (1999). Light intensity effects on pigment composition and organisation in the green sulfur bacterium Chlorobium tepidum. Photosynth Res 59: 159-166.

Bryant DA, Frigaard NU. (2006). Prokaryotic photosynthesis and phototrophy illuminated. Trends Microbiol 14: 488-496.

Buchanan BB, Arnon DI. (1990). A reverse KREBS cycle in photosynthesis: consensus at last. Photosynth Res 24: 47-53.

Burch MD. (1988). Annual cycle of phytoplankton in Ace Lake, an ice covered, saline meromictic lake. Hydrobiologica 165: 59-75.

Burke CM, Burton HR. (1988a). The ecology of photosynthetic bacteria in Burton Lake, Vestfold Hills, Antarctica. Hydrobiologia 165: 1-11.

Burke CM, Burton HR. (1988b). Photosynthetic bacteria in meromictic lakes and stratified fjords of the Vestfold Hills, Antarctica. Hydrobiologia 165: 13-23.

Burton HR. (1980). Methane in a saline Antarctic lake. In: Trudinger PA, Walter MR, Ralph, BJ (eds). Biogeochemistry of Ancient and Modern Environments. Australian Academy of Science: Canberra, Australia, pp 243-251.

Cavicchioli R. (2006). Cold-adapted Archaea. Nat Rev Microbiol 5: 331-343.

Chung S, Shen G, Ormerod J, Bryant DA. (1998). Insertional inactivation studies of the $\operatorname{csm} A$ and $\operatorname{csm} C$ genes of the green sulfur bacterium Chlorobium vibrioforme 8327: the chlorosome protein CsmA is required for viability but CsmC is dispensable. FEMS Microbiol Lett 164: 353-361.

Commichau FM, Forchhammer K, Stülke J. (2006). Regulatory links between carbon and nitrogen metabolism. Curr Opin Microbiol 9: 167-172.

Coolen MJL, Muyzer G, Schouten S, Volkman JK, Sinninghe Damsté JS. (2006). Sulfur and methane cycling during the Holocene in Ace Lake (Antarctica) revealed by lipid and DNA stratigraphy. In: Neretin, LN (ed.). Past and Present Marine Water Column Anoxia (NATO Science Series: IV-Earth and Environmental Sciences). Springer: Dordrecht, The Netherlands, pp 41-65.

de Mendoza D, Garwin JL, Cronan Jr JE. (1992). Overproduction of cis-vaccenic acid and altered temperature control of fatty acid synthesis in mutant Escherichia coli. J Bacteriol 151: 1608-1611.

Delcher AL, Harmon D, Kasif S, White O, Salzberg SL. (1999). Improved microbial gene identification with GLIMMER. Nucleic Acid Res 27: 4636-4641.

Eisen JA, Nelson KE, Paulsen IT, Heidelberg JF, Wu M, Dodson RJ et al. (2002). The complete genome sequence of Chlorobium tepidum TLS, a photosynthetic, anaerobic, green-sulfur bacterium. Proc Natl Acad Sci USA 99: 9509-9514.

Farr SB, Kogoma T. (1991). Oxidative stress response in Escherichia coli and Salmonella typhimurium. Microbiol Rev 55: 561-585.

Franzmann PD, Roberts NJ, Mancuso CA, Burton HR, McMeekin TA. (1991b). Methane production in meromictic Ace Lake, Antarctica. Hydrobiologica 210: 191-201.

Franzmann PD, Skyring GW, Burton HR, Deprez PP. (1988). Sulfate reduction rates and some aspects of limnology of four lakes and a fjord in the Vestfold Hills, Antarctica. Hydrobiologia 165: 25-33.

Frigaard NU, Bryant DA. (2004). Seeing green bacteria in a new light: genomics-enabled studies of the photosynthetic apparatus in green sulfur bacteria and filamentous anoxygenic phototrophic bacteria. Arch Microbiol 182: 265-276.

Frigaard NU, Bryant DA. (2006). Chlorosomes: antenna organelles in photosynthetic green bacteria. In: Shively JM (ed). Complex Intracellular Structures in Prokaryotes. Springer: Berlin, Germany, pp 79-114.

Frigaard NU, Bryant DA. (2008). Genomic insights into the sulfur metabolism of phototrophic green sulfur bacteria. In: Hell R, Dahl C, Knaff D, Leustek T (eds). Sulfur Metabolism in Phototrophic Organisms. Springer: New York, USA, pp 60-76.

Frigaard NU, Maresca JA, Yunker CE, Jones AD, Bryant DA. (2004). Genetic manipulation of carotenoid biosynthesis in the green sulfur bacterium Chlorobium tepidum. J Bacteriol 186: 5210-5220.

Frigaard NU, Matsuura K, Hirota M, Miller M, Cox RP. (1998). Studies of the location and function of isoprenoid quinones in chlorosomes from green sulfur bacteria. Photosynth Res 58: 81-90.

Fujita Y, Bauer CE. (2000). Reconstitution of light-independent protochlorophyllide reductase from purified $\mathrm{BChl}$ and BChN-BChB subunits. In vitro confirmation of nitrogenase-like features of a bacteriochlorophyll biosynthesis enzyme. J Biol Chem 275: 23583-23588.

Gatlin CL, Kleemann GR, Hayes LG, Link AJ, Yates III JR. (1998). Protein identification at the low femtomole level from silver-stained gels using a new fritless 
electrospray interface for liquid chromatographymicrospray and nanospray mass spectrometry. Anal Biochem 263: 93-101.

Giangrossi M, Giuliodori AM, Gualerzi CO, Pon CL. (2002). Selective expression of the $\beta$-subunit of nucleoid-associated protein HU during cold shock in Escherichia coli. Mol Microbiol 44: 205-216.

Gibson JAE. (1999). The meromictic lakes and stratified marine basins of the Vestfold Hills, East Antarctica. Antarct Sci 11: 175-192.

Gomez Maqueo Chew A, Frigaard NU, Bryant DA. (2007). Bacteriochlorophyllide $C \quad \mathrm{C}-8^{2}$ and $\mathrm{C}-12^{1}$ methyltransferases are essential for adaptation to low light in Chlorobaculum tepidum. J Bacteriol 189: 6176-6184.

Grau R, Gardiol D, Glikin GC, de Mendoza D. (1994). DNA supercoiling and thermal regulation of unsaturated fatty acid synthesis in Bacillus subtilis. Mol Microbiol 11: 933-941.

Graumann PL, Marahiel MA. (1999). Cold shock response in Bacillus subtilis. J Mol Microbiol Biotechnol 2: 203-209.

Griesbeck C, Schütz M, Schödl T, Bathe S, Nausch L, Mederer N et al. (2002). Mechanism of sulfide-quinone reductase investigated using site-directed mutagenesis and sulfur analysis. Biochemistry 41: 11552-11565.

Hauska G, Schoedl T, Remigy H, Tsiotis G. (2001). The reaction centre of green sulfur bacteria. Biochim Biophys Acta 1507: 260-277.

Heath RJ, Rock CO. (2002). The Claisen condensation in biology. Nat Prod Rep 19: 581-596.

Hohmann-Marriott M, Blankenship RE. (2007). Variable fluorescence in green sulfur bacteria. Biochim Biophys Acta 1769: 106-113.

Hunter WN. (2007). The non-mevalonate pathway of isoprenoid precursor biosynthesis. J Biol Chem 282: 21573-21577.

Imhoff JF. (2003). Phylogenetic taxonomy of the family Chlorobiaceae on the basis of 16S rRNA and fmo (Fenna-Matthews-Olson protein) gene sequence. Int $J$ Syst Evol Microbiol 53: 941-951.

Imlay JA. (2003). Pathways of oxidative damage. Annu Rev Microbiol 57: 395-418.

Kim H, Li H, Maresca JA, Bryant DA, Savikhin S. (2007). Triplet excitation formation as a novel photoprotection mechanism in chlorosomes in Chlorobium tepidum. Biophys J 93: 192-201.

Kurtz S, Phillippy A, Delcher AL, Smoot M, Shumway M, Antonescu C et al. (2004). Versatile and open software for comparing large genomes. Genome Biol 5: R12.

Lauro FM, McDougald D, Thomas T, Willams TJ, Egan S, Rice $S$ et al. (2009). The genomic basis of trophic strategy in marine bacteria. Proc Natl Acad Sci 106: 15527-15533.

Labourn-Parry J, Perriss SJ. (1995). The role and distribution of the autotrophic ciliate Mesodinium rubrum (Myrionecta rubra) in three Antarctic saline lakes. J Plankton Res 17: 1835-1850.

Li H, Bryant DA. (2009). Envelope proteins of the CsmB/ CsmF and CsmC/CsmD motif families inuence the size, shape, and composition of chlorosomes in Chlorobaculum tepidum. J Bacteriol 191: 7109-7120.

Li H, Jubelirer S, Costas AMG, Frigaard NU, Bryant DA. (2009). Multiple antioxidant proteins protect Chlorobaculum tepidum against oxygen and reactive oxygen species. Arch Microbiol 191: 853-867.
Lim J, Thomas T, Cavicchioli R. (2000). Low temperature regulated DEAD-box RNA helicase from Antarctic archaeon, Methanococcoides burtonii. J Mol Biol 297: 553-567.

Makihara F, Tsuzuki M, Sato K, Masuda S, Nagashima KV, Abo M et al. (2005). Role of trehalose synthesis pathways in salt tolerance mechanism of Rhodobacter sphaeroides f. sp. denitrificans IL106. Arch Microbiol 184: 56-65.

Mallorqui N, Arellano JB, Borrego CM, Garcia-Gil LJ. (2005). Signatures of green sulfur bacteria in lower Pleistocene deposits from the Banyoles lacustrine area (Spain). J Paleolimnol 34: 271-280.

Mansilla MC, Cybulski LE, Albanesi D, de Mendoza D. (2004). Control of membrane lipid fluidity by molecular thermosensors. J Bacteriol 186: 6681-6688.

Manske AK, Glaeser J, Kuypers MMM, Overmann J. (2005). Physiology and phylogeny of green sulfur bacteria forming a monospecific phototrophic assemblage at a depth of 100 meters in the Black Sea. Appl Environ Microbiol 71: 8049-8060.

Maresca JA, Bryant DA. (2006). Two genes encoding new carotenoid-modifying enzyme in the green sulfur bacterium Chlorobium tepidum. J Bacteriol 188: 6217-6223.

Maresca JA, Gomez Maqueo Chew A, Ponsatí MR, Frigaard NU, Ormerod JG, Bryant DA. (2004). The bchU gene of Chlorobium tepidum encodes the C-20 methyltransferase in bacteriochlorophyll $c$ biosynthesis. J Bacteriol 186: $2558-2566$.

Maresca JA, Romberger SP, Bryant DA. (2008). Isorenieratene biosynthesis in green sulfur bacteria requires the cooperative actions of two carotenoid cyclases. J Bacteriol 190: 6384-6391.

Martínez-Alonso M, van Bleijswijk J, Gaju N. (2005). Diversity of anoxygenic phototrophic sulfur bacteria in the microbial mats of the Ebro Delta: a combined morphological and molecular approach. FEMS Microbial Ecol 52: 339-350.

Mas J, Van Gemerden H. (1995). Storage products in purple and green sulfur bacteria. In: Blankenship RE, Madigan MT, Bauer CE (eds). Anoxygenic Photosynthetic Bacteria. Kluwer: Dordrecht, The Netherlands, pp 973-990.

Mizushima T, Kataoka K, Ogata Y, Inoue R, Sekimizu K. (1997). Increase in negative supercoiling of plasmid DNA in Escherichia coli exposed to cold shock. Mol Microbiol 23: 381-386.

Morgan-Kiss RM, Chan LK, Modla S, Weber TS, Warner M, Czymmek KJ et al. (2009). Chlorobaculum tepidum regulates chlorosome structure and function in response to temperature and electron donor availability. Photosynth Res 99: 11-21.

Musat N, Halm H, Winterholler B, Hoppe P, Peduzzi S, Hillion $\mathrm{F}$ et al. (2008). A single-cell view on the ecophysiology of anaerobic phototrophic bacteria. Proc Natl Acad Sci USA 105: 17861-17866.

Noguchi H, Park J, Takagi T. (2006). MetaGene: prokaryotic gene finding from environmental genome shotgun sequences. Nucleic Acids Res 34: 5623-5630.

Overmann J. (2006). The family Chlorobiaceae. In: Dworkin M, Falkow S, Rosenberg E, Schleifer KH, Stackebrandt E (eds). The Prokaryotes: A Handbook on the Biology of Bacteria. Springer: New York, USA, pp 359-378.

Overmann J, Garcia-Pichel F. (2006). The phototrophic way of life. In: Dworkin M, Falkow S (eds). The Prokaryotes: Ecophysiology and Biochemistry. Springer: New York, USA, pp 32-85. 
Overmann J, Pfennig N. (1989). Pelodictyon phaeoclathratiforme sp. nov., a new brown-coloured member of the Chlorobiaceae forming net-like colonies. Arch Microbiol 152: 401-406.

Pfennig N. (1975). The phototrophic bacteria and their role in sulfur cycling. Plant Soil 43: 1-16.

Pfennig N. (1978). General physiology and ecology of phototrophic bacteria. In: Clayton RK, Sistrom WR (eds). The Photosynthetic Bacteria. Plenum Press: New York, USA, pp 3-18.

Phillips JD, Whitby FG, Kushner JP, Hill CP. (2003). Stuctural basis for tetrapyrrole coordination by uroporphyrinogen decarboxylase. $E M B O \quad J \quad \mathbf{2 2}$ : 6225-6233.

Rankin LM, Gibson JAE, Franzmann PD, Burton HR. (1999). The chemical stratification and microbial communities of Ace Lake, Antarctica: a review of the characteristics of a marine-derived meromictic lake. Polarforschung 66: 35-52.

Rodrigues DF, Tiedji JM. (2008). Coping with our cold planet. Appl Environ Microbiol 74: 1677-1686.

Rodriguez-Brito B, Rohwer F, Edwards RA. (2006). An application of statistics to comparative metagenomics. BMC Bioinformatics 7: 162.

Rusch DB, Halpern AL, Sutton G, Heidelberg K, Williamson S, Yooseph S et al. (2007). The Sorcerer II Global Ocean Sampling Expedition: Northwest Atlantic through Eastern Tropical Pacific. PLoS Biol 5: e77.

Russell NJ. (2008). Membrane components and cold sensing. In: Margesin R, Schinner F, Marx JC, Gerday C (eds). Psychrophiles: From Biodiversity to Biotechnology. Springer: Berlin, Germany, pp 177-190.

Saunders NFW, Ng C, Raftery M, Guilhaus M, Goodchild A, Cavicchioli R. (2006). Proteomic and computational analysis of secreted proteins with type I signal peptides from the Antarctic archaeon. J Proteome Res 5: 2457-2464.
Sørensen PG, Cox RP, Miller M. (2007). Chlorosome lipids from Chlorobium tepidum: characterization and quantification of polar lipids and wax esters. Photosynth Res 95: 191-196.

Teeling H, Meyerdierks A, Bauer M, Amann R, Glöckner FO. (2004). Application of tetranucleotide frequencies for the assignment of genomic fragments. Environ Microbiol 6: 938-947.

Vila X, Guyoneaud R, Cristina XP, Figueras JB, Abella CA. (2002). Green sulfur bacteria from hypersaline Chiprana Lake (Monegros, Spain): habitat description and phylogenetic relationship of isolated strains. Photosynth Res 71: 165-172.

Volkman JK, Burton HR, Everitt DA, Allen DI. (1988). Pigment and lipid composition of algae and bacterial communities in Ace Lake, Vestfold Hills, Antarctica. Hydrobiologica 165: 41-57.

Wächtershäuser G. 1990. Evolution of the first metabolic cycles. Proc Natl Acad Sci USA 87: 200-204.

Wahlund TM, Woese CR, Castenholz RW, Madigan MT. (1991). A thermophilic green sulfur bacterium from New Zealand hot springs, Chlorobium tepidum sp. nov. Arch Microb 156: 81-90.

Ward DM, Ferris MJ, Nold SC, Bateson MM. (1998). A natural view of microbial diversity within hot spring cyanobacterial mat communities. Microbiol Mol Biol Rev 62: 1353-1370.

Willams T, Ertan H, Ting L, Cavicchioli R. (2009). Carbon and nitrogen substrate utilization in the marine bacterium Sphingopyxis alaskensis strain RB2256. ISME J 3: 1036-1052.

Yaronskaya E, Grimm B. (2006). The pathway from 5-aminolevulinic acid to protochlorophyllide and protoheme. In: Grimm B, Porra RJ, Rüdiger W, Scheer H (eds). Chlorophylls and Bacteriochlorophylls: Biochemistry, Biophysics, Functions and Applications. Springer: New York, USA, pp 173-188.

Supplementary Information accompanies the paper on The ISME Journal website (http://www.nature.com/ismej) 